ISSN 0854-9818

\title{
Bosques secundarios como recurso para el desarrollo rural y la conservación ambiental en los trópicos de América Latina
}

Joyotee Smith, César Sabogal, Wil de Jong y David Kaimowitz

CENTER FOR INTERNATIONAL FORESTRY RESEARCH

office address: Jalan CIFOR, Situ Gede, Sindangbarang, Bogor 16680, Indonesia mailing address: P.O. Box 6596 JKPWB, Jakarta 10065, Indonesia

tel.: +62 (251) 622622 fax: +62 (251) 622100

email: cifor@cgnet.com

$W W W:$ http://www.cgiar.org/cifor 


\section{The CGIAR System}

The Consultative Group on International Agricultural Research (CGIAR) is an informal association of 41 public and private sector donors that supports a network of sixteen international agricultural research institutes, CIFOR being the newest of these. The Group was established in 1971. The CGIAR Centers are part of a global agricultural research system which endeavour to apply international scientific capacity to solution of the problems of the world's disadvantaged people.

\section{CIFOR}

CIFOR was established under the CGIAR system in response to global concerns about the social, environmental and economic consequences of loss and degradation of forests. It operates through a series of highly decentralised partnerships with key institutions and/or individuals throughout the developing and industrialised worlds. The nature and duration of these partnerships are determined by the specific research problems being addressed. This research agenda is under constant review and is subject to change as the partners recognise new opportunities and problems. 


\section{Contenidos}

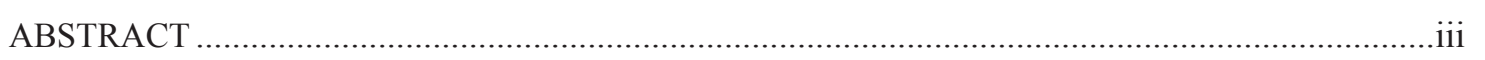

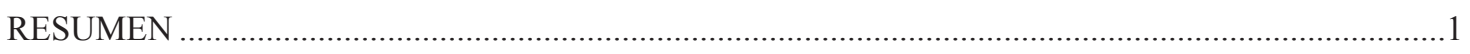

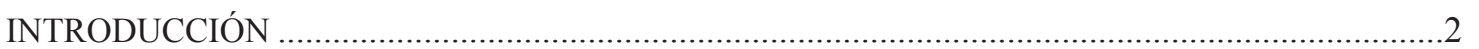

DEFINICIÓN DE BOSQUES SECUNDARIOS _................................................................................

EXTENSIÓN E IMPORTANCIA POTENCIAL DE LOS BOSQUES SECUNDARIOS .........................

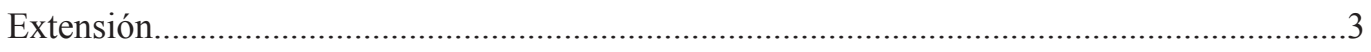

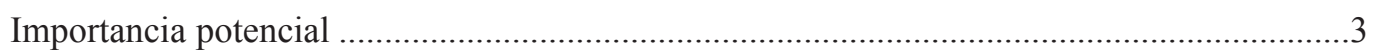

PRINCIPALES RASGOS ECOLÓGICOS DE LOS BOSQUES SECUNDARIOS..........................

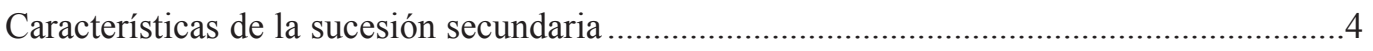

Factores que influencian la variabilidad de los bosques secundario ......................................

PROCESOS SOCIOECONÓMICOS DE FORMACIÓN Y RECONVERSIÓN

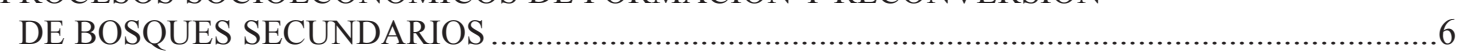

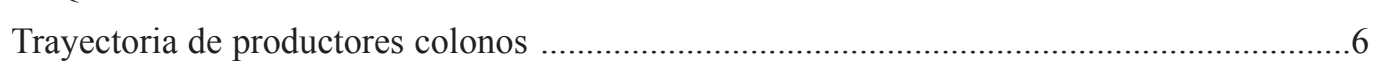

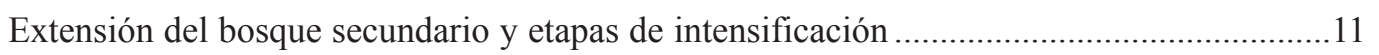

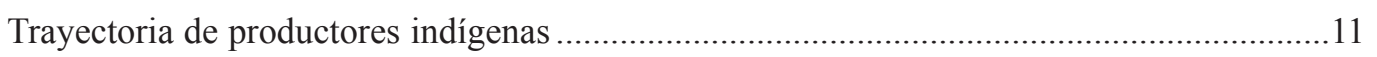

Dueños “accidentales", "paralizados" o "indiferentes"......................................................14

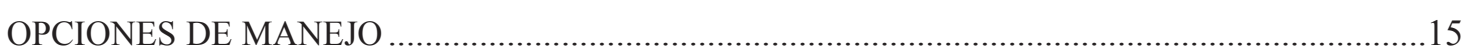

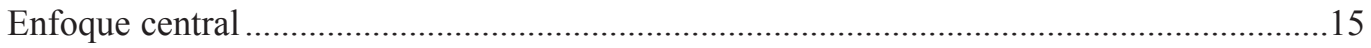

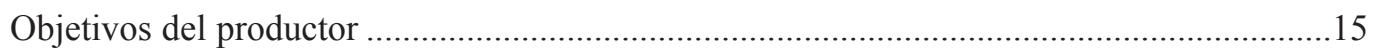

Opciones tecnológicas para el manejo .............................................................................16

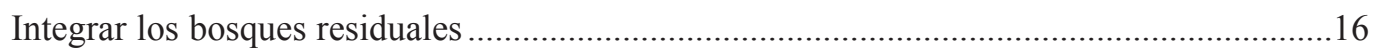

Relación entre opciones tecnológicas y características del productor ………........................17

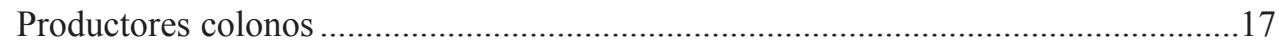

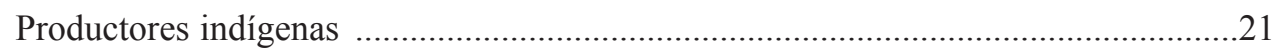

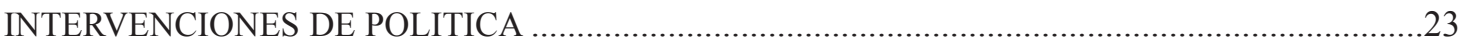

Políticas que pueden aumentar la rentabilidad de los bosques secundarios ..........................23

Correspondencia entre políticas y etapas de intensificación ..................................................24

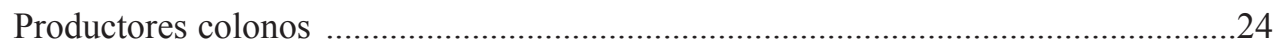

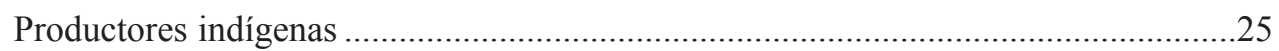

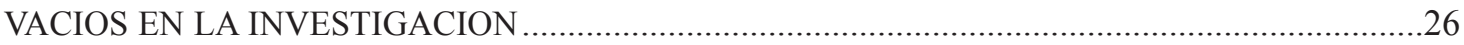

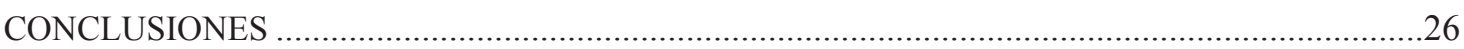

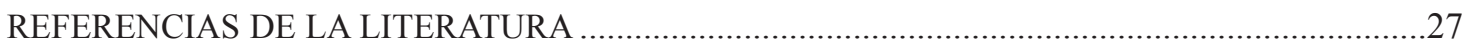




\title{
Abstract
}

\section{SECONDARY FORESTS AS A RESOURCE FOR PROMOTING RURAL DEVELOPMENT AND ENVIRONMENTAL CONSERVATION IN THE TROPICS OF LATIN AMERICA}

\begin{abstract}
Recent data show that destruction of primary forests has been accompanied by expansion in secondary forests. Studies also show that secondary forests are capable of providing some of the economic and ecological services of primary forests. This has led to a new strategy of increasing the value of secondary forests to farmers and cattle ranchers with the aim of inducing them to conserve these forests indefinitely or to at least delay reconversion to other uses. The objective of this paper is to contribute to a coherent strategy for realising the potential of secondary forests. We hypothesise that substantial areas of secondary forest exist on the farms of small and large land holders and that technical and political interventions can significantly increase the area and economic and environmental value of secondary forests and therefore the period for which they are conserved. We also hypothesise that secondary forests are highly variable in their ecological characteristics and also in the objectives and resources of their owners. Therefore the interventions required are likely to be highly variable. An analysis of the dynamics of secondary forests can help target interventions to those areas with the highest probability of impact.
\end{abstract}

We define secondary forests as "woody vegetation of a successional character which develops in areas whose original vegetation has been removed as a result of human intervention". The area in secondary forest in Latin America is estimated by FAO to be around 165 million ha. Studies have shown that growth rates of fast-growing timber species in secondary forests are comparable to growth rates attained in plantations. Secondary forests also accumulate biomass rapidly in the first 20-30 years and thus provide ecological services such as carbon sequestration and watershed protection. Vegetation studies in degraded and non-degraded areas have identified successional phases which differ in structure and floristic composition. Factors that determine the variability of secondary forests have been identified as prior land use, soil characteristics and proximity to seed sources.

Our analysis of the socio-economic aspects of the dynamics of secondary forests is based on the progressive change in the characteristics of frontier areas over time. We distinguish between two different trajectories: that followed by colonists and that of indigenous communities. Within the colonist trajectory we identify three stages: Early Pioneer, Emerging Markets and Old Frontier and distinguish between smallholders and large-scale cattle ranches. For indigenous communities the stages are Migratory Agriculture, Semi-sedentariness and Market Access. We also identify a third category of accidental circumstances, such as military conflicts and litigation, which lead to the creation of secondary forests. For each stage in each trajectory we qualitatively assess the objectives of producers, their level of access to resources, such as land, labour, capital and management capacity, their access to markets, tenure security and production system. We also qualitatively classify the secondary forests in terms of age, reason for existence, degree of management and exploitation of forest products, and their proximity to seed sources.

We next characterise management options for secondary forest according to their requirements of resources (capital, land, labour and management capacity) and the time lag required to obtain output. Three categories of management systems are identified: short-cycle improved fallows, enriched medium-cycle fallows, medium- and long-cycle production forests and conservation forests. We then match the characteristics of each category of producers and their secondary forests to the characteristics of management options to target options where the likelihood of adoption is highest. Results show that there is a high degree of variability in the type of management options appropriate for different categories of producers. Thus technology targeting could considerably improve the efficiency of technology generation. They also show that the appropriate management strategy for a particular forest can change over time as biophysical and socio-economic conditions change. This illustrates the 
importance of using a dynamic conceptual framework. The results indicate that none of the management options appear to be suitable for certain categories of producers who are likely to have the largest areas of secondary forest: large-scale ranchers in the early stages of frontier development and the category of "accidental owners". The results also indicate that indigenous communities in the Market Access stage may be more receptive to management options than colonists. The exercise identifies certain management options which do not appear to be appropriate for any producer category. It should be emphasised that the above results are primarily hypotheses based on a synthesis of the existing literature.

The broad categories of policy interventions appropriate for each category of producer are then identified. We distinguish between three categories of policies, specific to secondary forests: policies related to the marketing of secondary forest products, legislative reforms and policies which permit producers to capture the value of the environmental services provided by secondary forests (such as trade in carbon sequestration services). Our results show that the priority areas for policy interventions are the Emerging Market stage in the colonist trajectory and the Market Access stage in the indigenous community trajectory.

We conclude by emphasising the importance of a dynamic conceptual framework for the development of a strategy for secondary forests, as this permits the prevention of resource degradation, as opposed to reversing degradation after it occurs. The conceptual framework we present also allows the analysis of secondary forests as an integral part of the farmer's production system. Finally, we emphasise that the main contribution of this exercise is the conceptual framework. The results are merely indicative and need to be verified with empirical data. 


\title{
BOSQUES SECUNDARIOS COMO RECURSO PARA EL DESARROLLO RURAL Y LA CONSERVACIÓN AMBIENTAL EN LOS TRÓPICOS DE AMÉRICA LATINA ${ }^{1}$
}

\author{
Joyotee Smith, César Sabogal, Wil de Jong y David Kaimowitz
}

\begin{abstract}
Resumen
Datos recientes muestran que la destrucción de los bosques primarios ha estado acompañada por la expansión de los bosques secundarios. Los estudios también muestran que los bosques secundarios son capaces de proporcionar algunos de los servicios económicos y ecológicos de los bosques primarios. Esto ha conducido a una nueva estrategia para aumentar el valor de los bosques secundarios para agricultores y ganaderos, con el objetivo de inducirlos a conservar estos bosques indefinidamente, o al menos a retardar su reconversión a otros usos. El objetivo de este artículo es de contribuir a una estrategia coherente para realizar el potencial de los bosques secundarios. Nuestra hipótesis es de que existen áreas importantes bajo bosque secundario en terrenos de pequeños y grandes productores y que a través de intervenciones tecnológicas y de política se puede incrementar significativamente el área y el valor económico y ecológico de bosques secundarios y, por consiguiente, el periodo por el cual estos son conservados. También formulamos la hipótesis de que los bosques secundarios son altamente variables en sus características ecológicas y en términos de objetivos y recursos de sus propietarios. Por tanto, es probable que las intervenciones requeridas sean altamente variables. Un análisis de la dinámica de los bosques secundarios puede ayudar a dirigir las intervenciones a aquellas áreas con la más alta probabilidad de impacto.

El análisis de los aspectos socioeconómicos de la dinámica de bosques secundarios se basa en el cambio progresivo en el tiempo de algunas características de áreas de frontera agricola. Hacemos la distinción entre dos trayectorias diferentes: aquella seguida por colonos y la de comunidades indigenas. Una tercera categoría de circunstancias accidentales, tales como conflictos militares y litigio, también pueden conducir a la creación de bosques secundarios.

Las opciones de manejo para bosques secundarios se clasifican de acuerdo a sus requerimientos de recursos (capital, tierra, mano de obra y capacidad gerencial) y el transcurso de tiempo para obtener un producto, resultando cuatro grupos: barbechos mejorados de ciclo corto, barbechos enriquecidos de ciclo medio, bosques de producción de ciclo medio a largo, y bosques de conservación. Las características de cada categoría de productores y sus bosques secundarios son contrastados con las características de las opciones de manejo donde la probabilidad de adopción es la más alta.

Luego se identifican las categorías generales de intervenciones de política apropiadas para cada categoría de productor, siendo: políticas relacionadas al mercadeo de produtos del bosque secundario, reformas de la legislación y políticas que permiten a los productores capturar el valor de los servicios ambientales que suministran los bosques secundarios.

Concluimos enfatizando la importancia de un marco conceptual dinámico para el desarrollo de una estrategia para bosques secundarios, que permite prevenir la degradación del recurso, en oposición a revertir esta después de que ocurra. El marco conceptual que se presenta también permite el análisis de bosques secundarios como una parte integral del sistema de producción del agricultor. Finalmente, se enfatiza que la contribución principal de este ejercicio es el marco conceptual. Los resultados son meramente indicativos y necesitan ser verificados con datos empíricos.
\end{abstract} 1 Ponencia presentada al Taller Internacional sobre el Estado Actual y Potencial de Manejo y Desarrollo del Bosque Secundario
Tropical en América Latina, celebrado en Pucallpa, Perú, del 2 al 6 de junio de 1997.

El trabajo se ha realizado en el marco del Proyecto CIFOR/CATIE Manejo de Bosques Secundarios en América Tropical: Una investigación colaborativa y comparativa en la frontera bosque-agricultura. Este proyecto cuenta con un aporte financiero del Banco Inter-Americano de Desarrollo (BID) y la Agencia Española para la Cooperación Internacional (AECI). 


\section{INTRODUCCIÓN}

Hoy en día se reconoce ampliamente la importancia de los bosques tropicales como fuente de productos forestales y de servicios ambientales y recreacionales. Frente a las altas tasas de deforestación en los trópicos (FAO 1995), la reforestación de tierras agrícolas y pastizales abandonados ha constituido una de las estrategias clave para restaurar algunos de los servicios económicos y ecológicos de los bosques primarios. Esta ha sido una dura batalla, ya que requiere que tanto agricultores y ganaderos cambien el uso actual de la tierra. Sin embargo, datos recientes revelan un fenómeno anteriormente desapercibido: junto con la conversión de bosques primarios a otros usos de la tierra, agricultores y ganaderos han permitido en forma voluntaria que importantes y crecientes áreas reviertan hacia bosques secundarios (Dourojeanni 1987; Anderson 1990; Skole et al. 1994; Morán et al. 1994; Fearnside 1996). Simultáneamente, los ecólogos nos muestran ahora que los bosques húmedos tropicales, anteriormente considerados como altamente frágiles y difíciles de rehabilitar, son más resilientes de lo que se creía. Una creciente evidencia viene indicando que los bosques secundarios que se desarrollan después de la intervención humana pueden ser manejados para proporcionar muchos de los servicios ecológicos y económicos suministrados originalmente por los bosques primarios (Ewel 1980; Brown y Lugo 1990). Estos bosques poseen un conjunto de características biofísicas que armonizan bien con el manejo forestal, como son una alta productividad y una composición ecológicamente uniforme de especies arbóreas dominantes, lo cual simplifica su utilización y facilita su silvicultura (Wadsworth 1987).

La situación anterior ha dado lugar a una nueva estrategia enfocada hacia el aumento del valor de bosques secundarios para agricultores y ganaderos, a fin de persuadirles a mantener estos en forma indefinida como sistemas sostenibles de producción, o al menos demorar su reconversión a otros usos. Esta estrategia tiene el mérito de reforzar una tendencia ya visible y con ello aumentar las probabilidades de éxito. Al mismo tiempo, tiene el potencial de contribuir al desarrollo económico, elevando el bienestar de los habitantes rurales en las márgenes del bosque y estimulando industrias de valor agregado, al mismo tiempo que es capaz de suministrar servicios ambientales a nivel local, regional y global.

La presente contribución se centra en las tierras bajas húmedas tropicales de América Latina, lo que se justifica por ser la ecoregión más extensa en términos de cobertura boscosa y donde se concentra la deforestación actual, fenómeno que usualmente implica la conversión del bosque primario principalmente por pequeños agricultores para fines agropecuarios (Uhl 1982; Dourojeanni 1987; Brown y Lugo 1990; National Research Council 1993). Nuestro objetivo es contribuir al desarrollo de una estrategia coherente para viabilizar el potencial de los bosques secundarios. Planteamos la hipótesis de que existen importantes áreas de bosque secundario en las propiedades (fincas o parcelas) de agricultores y ganaderos de pequeña y gran escala en los trópicos húmedos latinoamericanos y que intervenciones tecnológicas y de política pueden aumentar significativamente el área de bosque secundario, su valor económico y ecológico y el periodo por el cual se mantienen. También planteamos la hipótesis de que los bosques secundarios son altamente variables, tanto en sus características ecológicas, como en los objetivos y recursos de sus propietarios y que, por tanto, la naturaleza de las intervenciones que se requieran y de su efectividad probablemente también sean altamente variables. Un análisis de la dinámica de bosques secundarios puede guiar a identificar y definir las intervenciones en áreas con el mayor potencial de impacto.

En este documento se proporcionan conceptos y definiciones sobre bosques secundarios. Seguidamente se analizan varios procesos socioeconómicos y biofísicos que conducen a la formación, el mantenimiento y la reconversión de bosques secundarios, y las difeentes características económicas y ecológicas resultantes. Luego se derivan hipótesis acerca de las condiciones bajo las cuales pueden justificarse intervenciones tecnológicas y de política, así como la naturaleza genérica de tales intervenciones. Dado que sólo recientemente es que se viene reconociendo la existencia y el potencial de los bosques secundarios, uno de los principales resultados de este ejercicio será identificar los vacíos en la información requerida para desarrollar una estrategia holística.

\section{DEFINICIÓN DE BOSQUES SECUNDARIOS}

Existen diversas definiciones para el término bosques secundarios en los trópicos húmedos. El rasgo común a cualquier definición es el disturbio o perturbación al ecosistema, pudiendo este ser causado u originado naturalmente (por fenómenos atmosféricos, geológicos, por la fauna silvestre, etc.), o bien por el hombre como actor principal (en cuyo caso se habla de disturbios de orígen antrópico). Estas últimas perturbaciones son, de lejos, más comunes y ocupan hoy en día una mayor superficie que las naturales, además de tener implicaciones más importantes sobre el uso de la tierra, el desarrollo rural y la conservación de los recursos naturales en general. ${ }^{2}$

\footnotetext{
2 Uhl y Nepstad (1990) muestran cómo las perturbaciones antrópicas difieren de las naturales en términos de magnitud, duración y frecuencia, e ilustran con casos de la Amazonía la respuesta de ecosistemas a varios tipos de perturbaciones. Los autores consideran que el estudio de las perturbaciones ofrece guías útiles para el manejo de bosques naturales y el uso racional de las tierras deforestadas.
} 
Los bosques antrópicos cubren una diversidad de tipos afectados de alguna forma por el disturbio humano, comprendiendo tanto bosques primarios previamente aprovechados para madera (bosques residuales) como bosques de segundo crecimiento, bosques sucesionales o los llamados barbechos forestales, los que se encuentran en un estado de reconstrucción después de su conversión total (Wadsworth 1987, 1993; Dourojeanni 1987; Brown y Lugo 1990; Lamprecht 1990; Sips 1993; National Research Council 1993; Weaver 1993; Sips et al. 1996).

Son estos últimos los que merecerán aquí la mayor atención. A continuación la definición que usaremos para referirnos al bosque secundario en su sentido estricto:

\section{Bosque secundario (bosque sucesional o barbecho forestal)}

Vegetación leñosa de caracter sucesional que se desarrolla sobre tierras cuya vegetación original fue destruida por actividades humanas. El grado de recuperación dependerá mayormente de la duración e intensidad del uso anterior por cultivos agrícolas o pastos, así como de la proximidad de fuentes de semillas para recolonizar el área disturbada.

Nótese que la anterior se basa en la definición originalmente propuesta por el CATIE (Finegan y Sabogal 1988; Finegan 1992), pero eliminando la palabra "abandonadas", ya que consideramos que conlleva un juicio de valores que contradice la ya extensa literatura documentando la diversidad de usos que el poblador (grupos indígenas, productores rurales) da a los barbechos forestales (Padoch et al. 1985; Dubois 1990; Brodie et al. 1997).

Conviene aclarar la distinción básica entre los bosques secundarios sucesionales y los bosques residuales. Estos últimos son esencialmente bosques primarios (referidos también como bosques altos, maduros o densos) que aún conservan la estructura y composición florística de un bosque primario no intervenido, ya que la extracción de madera (como producto principal) no los ha modificado drásticamente. Esta distinción es mucho más obvia en las condiciones prevalecientes en los neotrópicos, donde la extracción de madera es aún (altamente) selectiva, a diferencia de lo que ocurre en muchos bosques del Sudeste Asiático, donde la intensidad de aprovechamiento es varias veces mayor y así también el disturbio resultante.

A fin de determinar la extensión y los cambios entre las diferentes clases de cobertura forestal, un reciente informe de la FAO (FAO 1996) clasifica las áreas bajo bosque en cuatro clases, de acuerdo a varias condiciones: grados de densidad (bosque cerrado y bosque abierto), disturbio espacial (bosque fragmentado) y disturbio temporal (barbecho largo proveniente de la agricultura migratoria). El barbecho largo es definido como un "mosaico de árboles maduros, bosque secundario, varios estadíos de segundo crecimiento y áreas cultivadas, cubriendo estas últimas entre 5 y $30 \%$ del área total". Además, se define el barbecho corto como un "mosaico de bosque secundario joven, varias estadíos de segundo crecimiento y áreas cultivadas, cubriendo estas últimas entre el 30 y el 50\% del área total". Finalmente, el bosque fragmentado aparece como un "mosaico de áreas con y sin bosque, teniendo una proporción de bosque entre el 10 y el $70 \%$ del área total (promedio estimado: 33\%)".

\section{EXTENSIÓN E IMPORTANCIA POTENCIAL DE LOS BOSQUES SECUNDARIOS}

\section{Extensión}

Por la misma amplitud y diversidad de bosques que entrarían bajo el término "secundarios" y la dificultad de reflejar esto en las estadísticas nacionales, no es posible sino ofrecer estimados tentativos del área que actualmente ocupan los bosques secundarios sucesionales. Recurriendo a estadísticas de la FAO para 1990, en América Latina habrían unos 165 millones de hectáreas (= mill. ha). Sumando esta superficie al área estimada de bosques residuales (170 mill. ha), se tendrían 335 mill. ha de bosques intervenidos por actividades humanas (Sips et al. 1996). De otro lado, en su informe de 1982, la FAO estimaba el área de bosques secundarios en América Latina en 171 mill. ha, con casi un $60 \%$ de esta área originada directamente de la conversión de bosques no disturbados para uso agrícola (Brown y Lugo 1990). Así, aunque no contamos con cifras precisas, es evidente que el área bajo bosques secundarios es muy importante y se está incrementando fuertemente (National Research Council 1993; Weaver 1993; Morán et al. 1994; FAO 1995, 1996).

\section{Importancia potencial}

Desde hace ya casi 40 años se viene mencionando y repitiendo sobre la importancia creciente de la vegetación secundaria en los trópicos americanos (Budowski 1961; Gómez-Pompa y Vásquez-Yanes 1974, Gómez-Pompa et al. 1979) y la tendencia de las especies de rápido crecimiento y baja densidad de madera que prosperan en los bosques de segundo crecimiento para constituirse en el "recurso maderable del futuro" (Ewel 1980). En años más recientes, con la mayor preocupación por los fenómenos de deforestación y el rol de los bosques en la conservación del ambiente, se registra un aumento en la importancia que se atribuye a este recurso, tanto desde el punto de vista 
económico, como ecológico y social. En lo económico, los bosques secundarios son extremadamente productivos, con tasas de incremento de madera comparables a las de plantaciones con especies de rápido crecimiento (por ejemplo, Wadsworth 1993). Los bosques secundarios se constituyen en fuente de frutas, plantas medicinales, materiales de construcción, forraje para animales y madera de valor, así como para la restauración de la productividad del sitio y la reducción de poblaciones de pestes (Brown y Lugo 1990; Dourojeanni 1990; Serrâo 1994).

Los bosques secundarios son también de considerable importancia ecológica, en términos de crecimiento forestal, acumulación de biomasa, beneficios hidrológicos y de la biodiversidad (National Research Council 1993). Debido a que los bosques secundarios aumulan biomasa rápidamente durante los primeros 20 a 30 años, también son un reservorio importante de carbón atmosférico; de esta manera, incrementando la productividad de los bosques secundarios a través de su manejo se puede aumentar su rol potencial para contrarrestar el efecto invernadero (Fearnside y
Guimarâes 1996). De otro lado, esta misma característica se puede considerar como una ventaja para la conservación de los bosques primarios restantes (Dourojeanni 1990).

El Cuadro 1 resume los principales servicios ecológicos y económicos que los bosques secundarios potencialmente pueden proporcionar. El amplio rango de usos implica que el manejo de bosques secundarios puede adecuarse o acomodarse a las prioridades de los usuarios.

\section{PRINCIPALES RASGOS ECOLÓGICOS DE LOS BOSQUES SECUNDARIOS}

\section{Características de la sucesión secundaria}

La sucesión secundaria es el proceso ecológico caracterizado por cambios que se suceden en el ecosistema después de una perturbación natural o humana (Gómez-Pompa et al. 1979). Aunque en realidad se

Cuadro 1. Importancia ecológica y económica de los bosques secundarios Algunos de los usos/valores son todavía potenciales.

\begin{tabular}{|c|c|}
\hline $\begin{array}{c}\text { Importancia ecológica (para la producción y la } \\
\text { conservación ambiental) }\end{array}$ & Importancia económica (como fuente de) \\
\hline $\begin{array}{l}\text { - Recuperación de la productividad del sitio (reservorio } \\
\text { de materia orgánica y nutrientes en el suelo para fines } \\
\text { de producción agrícola) } \\
\text { - Reducción de poblaciones de malezas y pestes } \\
\text { - Regulación de flujos de agua (beneficios hidrológicos) } \\
\text { - Reducción de la erosión del suelo y protección contra } \\
\text { el viento } \\
\text { - Mantenimiento de biodiversidad, especialmente cuando } \\
\text { la intensidad de uso de la tierra es alta y hay una } \\
\text { mayor fragmentación de bosques (Ejm: refugio/habitat } \\
\text { para ciertas especies de fauna cinegética) } \\
\text { - Acumulación de carbono (reservorio de carbono atmosférico) } \\
\text { - Servir como ecosistema para el establecimiento de especies de } \\
\text { plantas y animales que requieren decondiciones de bosque alto) } \\
\text { - Servir como modelo para el diseño de agrocosistemas } \\
\text { (Ejm.: sistemas multi-propósito) } \\
\text { - Servir de reserva para áreas a ser usadas para la agricultura } \\
\text { y/o ganadería } \\
\text { Contribuir a reducir la presión sobre los bosques } \\
\text { primarios (“vírgenes" o residuales) / Un caso sería } \\
\text { en áreas de amortiguamiento para proteger reservas } \\
\text { de bosques }\end{array}$ & $\begin{array}{l}\text { - } \text { Frutos comestibles } \\
\text { Plantas alimenticias, medicinales, estimulantes, } \\
\text { - Materiales para construcción rural y cercas } \\
\text { - Combustible (leña, carbón) } \\
\text { - Combustible (leña, carbón) } \\
\text { - Tecnología: materiales para teñir; materiales } \\
\text { para elaborar utensilios domésticos y de caza, } \\
\text { para servir de adorno y en ceremonias, etc. } \\
\text { - Madera de valor } \\
\text { - Madera para uso industrial (madera aserrada, } \\
\text { traslapada, laminada, tableros de fibra y partículas) } \\
\text { - Carne silvestre (proteína animal, cueros, etc.) } \\
\text { - Germoplasma de especies útiles para fines de } \\
\text { domesticación (Ejm., para establecer plantaciones } \\
\text { agroforestales multi-propósito, o bien de árboles } \\
\text { maderables de rápido crecimiento) } \\
\text { - Ramoneo de animales y preparación de alimento } \\
\text { para ganado } \\
\text { Transformación química de la biomasa } \\
\text { (fabricación de pulpa y papel, plásticos y fibras } \\
\text { celulósicas; gasificación de la madera...) }\end{array}$ \\
\hline
\end{tabular}

* Fuentes: Budowski 1961; Gómez-Pompa et al. 1979; Ewel 1981; Fontaine et al. 1978; Dourojeanni 1987, 1990; Denich 1989; Brown y Lugo 1990; Dubois 1990; Sips 1993; Serrâo 1994; Villachica 1995; Fearnside y Guimarâes 1996; Cámara Nacional Forestal 1996; Brodie et al. 1997. 
trata de un continuum en el proceso sucesional, se reconoce que este se puede dividir en varias etapas, estadíos o fases. Se han propuesto diferentes modelos para representar las sucesiones secundarias en los neotrópicos húmedos (por ejemplo, Budowski 1961, 1965; Gómez-Pompa y Vásquez-Yanes 1974; Gräfe 1981; Kahn 1982; Denich 1989), los cuales reconocen tres fases durante las primeras décadas de la sucesión. ${ }^{3}$ Con un enfoque pragmático, los trabajos iniciales se basaron en las especies comunes del dosel, o bien en los grupos ecológicos al que aparentemente pertenecían estas especies (Finegan 1991). Sin embargo, por el interés creciente en la biodiversidad forestal, el énfasis de trabajos más recientes tiende a enfatizar las tendencias en la riqueza de especies, a menudo sin considerar su composición o identidad florística (Finegan 1996). Finegan $(1992,1996)$ habla de la existencia de un grado de concenso en un modelo descriptivo general de las sucesiones secundarias en los neotrópicos, que sería válido allí donde el suelo no ha sido degradado y hay fuentes cercanas de semillas. Los primeros 100 años de la sucesión se pueden describir en términos de tres fases, durante las cuales ocurren cambios en la estructura (altura del dosel, densidad y área basal de árboles) y composición florística (riqueza y diversidad de especies).

Un estudio particularmente importante es el realizado en San Carlos de Río Negro, Amazonía Venezolana por Saldarriaga. Saldarriaga y Uhl (1987) documentan una larga cronosecuencia de la sucesión luego de prácticas agrícolas de tala y quema, desde parcelas abandonadas a bosques maduros. Estos autores encontraron que durante los primeros 10 a 20 años de la sucesión las especies pioneras dominan, principalmente los miembros del género Vismia. A los 30 y 40 años, las "especies sucesionales tempranas" son reemplazadas por grupos de otras especies de rápido crecimiento y más persistentes, tales como Vochysia sp., Alchornea sp. y Jacaranda copaia, las cuales llegan a ser dominantes por los siguientes 50 años, y, en algunos casos, pueden continuar siendo importantes en los bosques maduros. Los mayores cambios de especies acontecen en rodales de 40-80 años, cuando ocurren eventos significativos, principalmente la aper- tura de claros del dosel por muerte de árboles dominantes; el tamaño de estos claros determina cuáles especies ocuparán el sitio. Del estudio se concluye, entre otros, que la diversidad de especies aumenta a través del tiempo de la sucesión y que la tasa de recuperación de la composición florística, estructura y biomasa que sigue al disturbio es relativamente lenta. Los autores estiman que se requerirían aproximadamente entre 140 y 200 años para que una parcela abandonada alcance los niveles de biomasa comparables al bosque maduro.

\section{Factores que influencian la variabilidad de los bosques secundario}

Una de las características más sobresalientes de los bosques secundarios es la gran variabilidad florística que presentan sus rodales dentro de cortas distancias, tanto a nivel de dosel como de vegetación de sotobosque (por ejemplo, Zimmermann et al. 1995; Guariguata et al. en prensa). Esto es debido principalmente a variaciones fenológicas de especies colonizadoras al momento del abandono del terreno, al tipo de regeneración (rebrotes vs. semillas), así como a la presencia de diferentes especies de árboles remanentes, los cuales pueden influenciar la composición del sitio. A escala regional, sin embargo, efectos abióticos como diferencias en precipitación y elevación (Ewel 1980) determinan en mayor parte la velocidad de la sucesión.

A pesar de esta inherente variabilidad composicional dentro de una misma zona de vida, otros factores como uso anterior de la tierra, fertilidad del suelo y proximidad a fuentes de propágulos, interactœan para ejercer un papel crítico en la recuperación del sitio, ya sea en términos estructurales (biomasa, altura, o área basal) o florísticos. En general, la recuperación de atributos estructurales es función inversa del grado de degradación del sitio y función directa del nivel de fertilidad del suelo (Uhl et al. 1988; Nepstad et al. 1990). Por ejemplo, la recuperación en área basal con respecto al bosque maduro luego de la tala y quema (Saldarriaga et al. 1988) o el aprovechamiento forestal a tala rasa (Faber-Langendôen 1992) en oxisoles en Sudamérica, es aparentemente mucho más lenta que la observada en bosques secundarios desarrollados sobre

\footnotetext{
3 Las etapas sucesionales reciben variados nombres, que pueden diferir de país a país, o aún de zona a zona o localidad dentro de un país, dependiendo de los grupos étnicos o lingüísticos, el tipo de productor, las costumbres locales, etc. Términos como 'purma' en Perú; 'capoeira' en ciertas partes del Brasil, 'charral', 'tacotal'o 'guamil' en Centroamérica, tienden a referirse al barbecho en general, sin dar una mayor indicación sobre su grado de desarrollo. Para esto, con frecuencia se incluye una referencia a la edad con palabras como joven, intermedio o viejo (adulto o maduro). Sin embargo, se conoce de pueblos que tuvieron (y aún conservan una terminología bastante elaborada para referirse a los distintos tipos de barbechos forestales, evidenciando su habilidad para manejar estos ecosistemas. Por ejemplo, Gómez-Pompa (1991) muestra cómo los mayas clasificaban la vegetación según la edad de la sucesión. Balée y Gély (1989) lo ilustran para el caso de los indígenas Ka'apor en la Amazonía del Brasil. Homma et al. (1993) hacen referencia a los diferentes términos que usan los caboclos (mestizos) en la Amazonía brasilera: 'juquira' para la vegetación secundaria con hasta 2 años de edad, 'capoeirinha' para la vegetación entre 2 y 4 años de edad, 'capoeira' para edades entre 4 y 10 años y 'capoeirao' cuando es mayor de 10 años de edad.
} 
suelos provenientes de depósitos volcánicos fértiles en Costa Rica (Finegan y Sabogal 1988; Guillén 1993). Dichas tendencias en recuperación estructural de la vegetación a través de gradientes de fertilidad del suelo han sido también reportados por Morán et al. (1996) a lo largo de la Amazonía.

A nivel florístico, el tipo e intensidad de uso anterior del sitio también determina la recuperación de la composición y riqueza de especies. Si la intensidad de uso ha sido leve, la recuperación (aunque no la composición) de la riqueza de especies es relativamente rápida (Uhl et al. 1988). A nivel de tipo de uso anterior, sin embargo, los patrones de composición florística suelen estar determinados, entre otros factores, por: (1) la presencia de aquellas especies capaces de tolerar suelos compactados, o baja fertilidad del suelo, y (2) la dominancia de ciertas especies al comenzar la sucesión (influenciado a su vez por el factor anterior), que pueden inhibir $y / 0$ facilitar el arribo de futuras especies colonizadoras. Además, si el grado de proximidad a fuentes semilleras es alto (Guariguata et al. en prensa) y existe presencia de especies leñosas capaces de atraer dispersores (Guevara et al. 1986; Nepstad et al. 1991), se espera que la recuperación florística sea relativamente rápida.

\section{PROCESOS SOCIOECONÓMICOS DE FORMACIÓN Y RECONVERSIÓN DE BOSQUES SECUNDARIOS}

La naturaleza y efectividad de las intervenciones tecnológicas y de política en el manejo de bosques secundarios dependerán de las características biofísicas de los bosques secundarios y de los objetivos y recursos de aquellos que los poseen y manejan. Estas características, a su vez, son determinadas por los procesos socioeconómicos y biofísicos que dan lugar a la formación y reconversión de bosques secundarios. La sección anterior describió los factores que con probabilidad afectan las características biofísicas de los bosques secundarios. Esta sección enfocará los procesos socioeconómicos que conducen a la formación de bosques secundarios. De allí se desarrollan hipótesis acerca de las características biofísicas resultantes y del potencial de los bosques secundarios para proporcionar servicios económicos y ecológicos

Conceptualmente, nuestra síntesis de procesos socioeconómicos en las áreas de frontera de bosque combina una dimensión temporal inspirada en teorías de intensificación del uso de la tierra y una dimensión espacial basada en teorías de zonación del uso de la tierra. Ambas dimensiones interaccionan con las dimensiones biofísicas y de políticas, las cuales modifican los patrones predichos por la teoría.

Las teorías de intensificación del uso de la tierra predicen que, con el tiempo, al aumentar la densidad poblacional y presentarse una escasez de tierra en relación a la mano de obra, los agricultores buscan aumentar el retorno de la tierra acortando los periodos de barbecho e invirtiendo más mano de obra y capital por unidad de tierra (Boserup 1965). Además, la frontera agrícola se expande al aumentar la población (Nerlove y Sadka 1991; Thiele 1995). Las teorías de zonación del uso de la tierra muestran que áreas cercanas a los centros de mercado tienen barbechos más cortos, inversiones más altas de mano de obra y capital por unidad de tierra, mayor procesamiento del producto (Nerlove y Sadka 1991; Jones y O’Neill 1993) y un mayor cumplimiento de la ley (Schneider 1995). Mejoras en el transporte y la aparición de signos de crecimiento de mercados conllevan a los mismos cambios y, además, expanden la frontera agrícola al hacer viable la producción en áreas más distantes (Nerlove y Sadka 1991). Estos procesos temporales y espaciales entran en interacción con diferencias biofísicas y de política y dan lugar a diversas trayectorias a través de las cuales se forman y reconvierten los bosques secundarios, como se muestra más abajo.

Debe enfatizarse aquí que las trayectorias a que nos referiremos seguidamente son mayormente hipótesis derivadas de la teoría y de información empírica dispersa. El objetivo de este ejercicio es básicamente demostrar la utilidad del marco conceptual propuesto. Ciertamente, se requiere de mucha más información empírica para verificar las trayectorias hipotéticas.

Empezamos distinguiendo entre dos tipos de trayectoria: la seguida por colonos en zonas de frontera agrícola y la de pobladores indígenas, etnicos o quasietnicos, como por ejemplo los ribereños en Peru y los caboclos en Brazil. Luego se identifica un tercer juego de factores "accidentales" que pueden conducir a la formación de bosques secundarios.

\section{Trayectoria de productores colonos}

Para este grupo se usarán las tres etapas identificadas por Richards (1996), con algunas modificaciones:

Etapa pionera temprana. Es cuando el frente pionero se abre por primera vez. Por lo común, se trata de una área remota con una densidad poblacional muy baja, transporte muy pobre (lo que reduce la rentabilidad de las actividades económicas) y una infraestructura social mínima. En vista de estas características, los inmigrantes tienden a contar con niveles relativamente bajos de capital físico y humano (Schneider 1995). El bosque primario es abundante, aunque con frecuencia las especies más valiosas ya han sido extraídas por los madereros. La tenencia de la tierra es generalmente insegura. La mano de obra y el capital son escasos. Los objetivos de los inmigrantes son el sobrevivir, plantar cultivos de subsistencia y acumular capital, esto último por lo general a través del aumento del valor de la tierra por conversión a pasturas o agricultura y como resultado de mejoras esperadas en la infraestructura de 
Cuadro 2. Características de los productores según las etapas de intensificación: productores 'colonos' en zonas de frontera agrícola.

\begin{tabular}{|c|c|c|c|c|c|c|}
\hline ETAPAS & \multicolumn{2}{|c|}{ Pionera temprana } & \multicolumn{2}{|c|}{ Mercados emergentes } & \multicolumn{2}{|c|}{ Frontera vieja } \\
\hline $\begin{array}{l}\text { Caracter } \\
\text { de product }\end{array}$ & $\begin{array}{l}\text { Escala } \\
\text { pequeña }\end{array}$ & $\begin{array}{l}\text { Escala } \\
\text { grande }\end{array}$ & $\begin{array}{l}\text { Escala } \\
\text { pequeña }\end{array}$ & $\begin{array}{l}\text { Escala } \\
\text { grande }\end{array}$ & $\begin{array}{l}\text { Escala } \\
\text { pequeña }\end{array}$ & $\begin{array}{l}\text { Escala } \\
\text { grande }\end{array}$ \\
\hline $\begin{array}{l}\text { Objectivos } \\
\text { generales }\end{array}$ & $\begin{array}{l}\text { subsistencia; } \\
\text { valorización } \\
\text { de la tierra }\end{array}$ & $\begin{array}{l}\text { especulación } \\
\text { de la tierra }\end{array}$ & $\begin{array}{l}\text { subsistencia } \\
\text { y producción } \\
\text { comercial }\end{array}$ & $\begin{array}{l}\text { especulación } \\
\text { de la tierra }\end{array}$ & $\begin{array}{l}\text { producción } \\
\text { comercial y } \\
\text { subsistencia }\end{array}$ & $\begin{array}{l}\text { producción } \\
\text { comercial y } \\
\text { especulación }\end{array}$ \\
\hline Recursos & $\begin{array}{l}\text { capital/mano } \\
\text { de obra: } \\
\text { escasos } \\
\text { capacidad } \\
\text { gerencial: } \\
\text { escasa }\end{array}$ & $\begin{array}{l}\text { capital/tierra } \\
\text { abundantes } \\
\text { mano de } \\
\text { obra/capac. } \\
\text { gerencial: } \\
\text { escasas }\end{array}$ & $\begin{array}{l}\text { capital/mano } \\
\text { de obra: } \\
\text { escasos a } \\
\text { mod. abund. } \\
\text { tierra: } \\
\text { moderad. } \\
\text { abundante } \\
\text { cap. gerencial: } \\
\text { escasa }\end{array}$ & $\begin{array}{l}\text { capital/tierra: } \\
\text { abundante } \\
\text { mano de } \\
\text { obra/capac. } \\
\text { gerencial: } \\
\text { escasas }\end{array}$ & $\begin{array}{l}\text { tierra: } \\
\text { escasa } \\
\text { capital/capac } \\
\text { gerencial: } \\
\text { moderados } \\
\text { mano de } \\
\text { obra: } \\
\text { abundante }\end{array}$ & $\begin{array}{l}\text { tierra: } \\
\text { moderada } \\
\text { capital/capac } \\
\text { gerencial: } \\
\text { abundantes } \\
\text { mano de } \\
\text { obra: } \\
\text { moderada }\end{array}$ \\
\hline $\begin{array}{l}\text { Acceso a } \\
\text { mercados }\end{array}$ & pobre & pobre & moderado & moderado & bueno & bueno \\
\hline $\begin{array}{l}\text { Tenencia de } \\
\text { la tierra }\end{array}$ & insegura & insegura & $\begin{array}{l}\text { moderad. } \\
\text { insegura }\end{array}$ & segura & segura & segura \\
\hline $\begin{array}{l}\text { Sistemas de } \\
\text { producción }\end{array}$ & agricultura & ganadería & $\begin{array}{l}\text { agricultura } \\
\text { ganadería de } \\
\text { doble } \\
\text { propósito/pe } \\
\text { rennes } \\
\text { (agricultores } \\
\text { con más } \\
\text { recursos) }\end{array}$ & ganadería & $\begin{array}{l}\text { agricultura } \\
\text { ganadería de } \\
\text { doble } \\
\text { propósito/pe } \\
\text { rennes } \\
\text { (agricultores } \\
\text { con más } \\
\text { recursos) }\end{array}$ & $\begin{array}{l}\text { ganadería } \\
\text { agricultura } \\
\text { mecanizada }\end{array}$ \\
\hline $\begin{array}{l}\text { Disponibilidad } \\
\text { de bosques } \\
\text { primarios }\end{array}$ & abundante & escaso & $\begin{array}{l}\text { llegando a } \\
\text { ser escaso }\end{array}$ & escaso & escaso & escaso \\
\hline
\end{tabular}

transporte. Así, en esta etapa los inmigrantes a menudo son transitorios, buscando vender y moverse a una nueva frontera, por lo que es poco probable que estén interesados en inversiones a largo plazo. La agricultura tiene un fuerte componente de subsistencia. Las necesidades de dinero se buscan satisfacer a través de diversas actividades de baja intensidad, tales como la cría de animales menores (Cuadro 2).

La tierra es deforestada de forma progresiva, empezando por lo general del área más próxima al camino; sin embargo, quedan todavía áreas importantes de bosque primario. No hay escasez de productos forestales. Debido a las limitaciones de mano de obra y capital, sólo una pequeña parte del área deforestada está bajo cultivo a un mismo tiempo. Se practica la agricultura de tala y quema, con una variedad de periodos de barbecho y secuencias de cultivo. La duración de los barbechos es seleccionada para maximizar el retorno al gasto en mano de obra, tomando en cuenta que barbechos largos requieren de más mano de obra para el desbosque, mientras que barbechos cortos requieren de mayor trabajo para los desmalezamientos. En muchas áreas, las limitaciones de mano de obra para el desbosque son superadas a través del trabajo en grupos, el cual se lleva a cabo en forma secuencial en los campos de los miembros del grupo. Se esperaría que esto, más la abundancia de tierras, llevarían a una preferencia por barbechos largos. En la práctica, no obstante, se escoge una variedad de periodos de barbecho debido a diferencias en la calidad de suelo entre 
las parcelas, la distancia de la vivienda, etc. De esta manera, lo que resulta es un mosaico consistente de campos de cultivo y barbechos (incluyendo bosques secundarios) de diferentes edades (Walker y Homma 1996; Scatena et al. 1996).

Esta descripción implica que en la etapa pionera temprana existen crecientes áreas de bosques secundarios para recuperar la productividad agrícola y también porque los agricultores no cuentan con suficiente mano de obra y capital para cultivar áreas mayores. Se esperaría que los bosques secundarios sean parte de un mosaico de diferentes usos de la tierra, incluyendo el bosque primario (residual) y barbechos de edades diferentes. El uso de la tierra anterior al barbecho probablemente sea relativamente de baja intensidad debido a la abundancia de tierras. Se conoce muy poco si es que los bosques secundarios se usan o manejan de alguna manera, aunque se podría especular aquí que es muy poco probable, dada la abundancia de bosque primario (Cuadro 3).
En estas situaciones, el potencial ecológico de los bosques secundarios sería alto, dado que el suelo aún no ha sido utilizado intensamente (unos pocos ciclos de cultivos anuales) y hay una buena disponibilidad de fuentes de semillas para la colonización en la etapa inicial del barbecho. En parte, estas provendrían de árboles remanentes que, además de su valor utilitario (por ejemplo, frutos, madera de calidad, etc.), cumplen un rol ecológico importante (Guevara et al. 1986). Además, podría esperarse que en la regeneración que se desarrolla ocurran especies de valor económico que lleguen a dominar, si se deja desarrollar la sucesión secundaria (Finegan 1992).

Los bosques secundarios también pueden surgir en la etapa pionera temprana como resultado de incentivos del gobierno para la ganadería, tal como ocurrió en Brasil y varios países Centroamericanos. Esto puede causar que ganaderos no residentes deforesten $\mathrm{y}$ establezcan pasturas en áreas muy alejadas de la frontera agrícola, las que son demasiado remotas para una

Cuadro 3. Características de los bosques secundarios según las etapas de intensificación: productores "colonos" en zonas de frontera agrícola.

\begin{tabular}{|c|c|c|c|c|c|c|}
\hline ETAPAS & \multicolumn{2}{|c|}{ Pionera temprana } & \multicolumn{2}{|c|}{ Mercados emergentes } & \multicolumn{2}{|c|}{ Frontera vieja } \\
\hline $\begin{array}{l}\text { Caracter } \\
\text { de product }\end{array}$ & $\begin{array}{c}\text { Escala } \\
\text { pequeña }\end{array}$ & $\begin{array}{l}\text { Escala } \\
\text { grande }\end{array}$ & $\begin{array}{c}\text { Escala } \\
\text { pequeña }\end{array}$ & $\begin{array}{c}\text { Escala } \\
\text { grande }\end{array}$ & $\begin{array}{c}\text { Escala } \\
\text { pequeña }\end{array}$ & $\begin{array}{c}\text { Escala } \\
\text { grande }\end{array}$ \\
\hline Area y edad & $\begin{array}{l}\text { en aumento; } \\
\text { alguna mezcla } \\
\text { de edades }\end{array}$ & $\begin{array}{l}\text { grande; } \\
\text { mezcla de } \\
\text { edades? }\end{array}$ & $\begin{array}{l}\text { sustancial; } \\
\text { mezcla de } \\
\text { edades }\end{array}$ & $\begin{array}{l}\text { grande; } \\
\text { mezcla de } \\
\text { edades }\end{array}$ & $\begin{array}{l}\text { mínima; } \\
\text { principalm. } \\
\text { jóvenes }\end{array}$ & $\begin{array}{l}\text { mínima; } \\
\text { principalm. } \\
\text { viejos }\end{array}$ \\
\hline $\begin{array}{l}\text { Razón de } \\
\text { existencia }\end{array}$ & $\begin{array}{l}\text { recuperación } \\
\text { de suelo; falta } \\
\text { de capital }\end{array}$ & $\begin{array}{l}\text { producción } \\
\text { no es impor- } \\
\text { tante }\end{array}$ & $\begin{array}{l}\text { recuperación } \\
\text { de suelo; } \\
\text { productos } \\
\text { forestales; } \\
\text { diversificación; } \\
\text { falta de capital; } \\
\text { servicios } \\
\text { ambientales? }\end{array}$ & $\begin{array}{l}\text { producción } \\
\text { no es } \\
\text { importante; } \\
\text { pasturas degra- } \\
\text { dadas; } \\
\text { servicios } \\
\text { ambientales? }\end{array}$ & $\begin{array}{l}\text { suelo inade- } \\
\text { cuado; } \\
\text { diversificación; } \\
\text { recuperación } \\
\text { de suelo; } \\
\text { servicios } \\
\text { ambientales? }\end{array}$ & $\begin{array}{l}\text { suelo inade- } \\
\text { cuado; } \\
\text { servicios } \\
\text { ambientales? }\end{array}$ \\
\hline Importancia & mínima & $\begin{array}{l}\text { mínima? } \\
\text { madera? }\end{array}$ & media & $\begin{array}{l}\text { mínima? } \\
\text { Madera? }\end{array}$ & baja & $\begin{array}{l}\text { mínima? } \\
\text { madera? }\end{array}$ \\
\hline $\begin{array}{l}\text { Usos de los } \\
\text { productos }\end{array}$ & mínimo? & $\begin{array}{l}\text { mínimo? } \\
\text { madera? }\end{array}$ & $\begin{array}{l}\text { subsistencia } \\
\text { leña, postes, } \\
\text { animales de } \\
\text { caza comercial: } \\
\text { frutas, madera }\end{array}$ & $\begin{array}{l}\text { mínimo? } \\
\text { madera? }\end{array}$ & $\begin{array}{l}\text { frutas, } \\
\text { madera }\end{array}$ & $\begin{array}{l}\text { mínimo? } \\
\text { madera? }\end{array}$ \\
\hline $\begin{array}{l}\text { Potencial } \\
\text { económico y } \\
\text { ecológico }\end{array}$ & alto & alto & moderado? & reducido? & bajo & bajo \\
\hline $\begin{array}{l}\text { Proximidad } \\
\text { al bosque } \\
\text { primario }\end{array}$ & sí & no & variable? & No & no & no \\
\hline
\end{tabular}


producción ganadera económicamente viable (Schneider 1995). Dado que el motivo principal es la especulación de la tierra, el establecimiento de la propiedad de la tierra y la captura de los incentivos a la ganadería, las pasturas son con frecuencia abandonadas y se desarrollan bosques secundarios. En esta situación, podríamos esperar grandes áreas de bosque secundario contiguo, relativamente distantes del bosque primario y situados en tierras poco degradadas. Nuevamente, se puede especular aquí que el uso de los bosques secundarios es muy bajo o hasta inexistente. Por otro lado, los ganaderos bien podrían aprovechar la madera, si es que hay suficientes especies valiosas para justificar los altos costos de transporte.

Etapa de mercados emergentes. En esta etapa se mejoran el transporte, la infraestructura, la seguridad en la tenencia de la tierra y el cumplimiento de la ley, dando lugar a oportunidades de mercado. Las oportunidades de mercado y las mejores condiciones de vida atraen a una segunda "oleada" de colonos (con algo más de capital humano y físico), los que son capaces de emprender actividades que dan retornos más altos al capital y la mano de obra que en la etapa pionera temprana (Schneider 1995). Aquellos colonos pioneros que no acumularon suficiente capital para alcanzar estos niveles de retorno, se ven forzados a vender la tierra y se trasladan a otro frente pionero o a áreas urbanas.

En esta etapa aún permanecen en las fincas áreas importantes de bosque primario. Mano de obra y capital, antes que tierra, siguen siendo los factores escasos. A fin de aprovechar las oportunidades de mercado, se deforestan y ponen bajo cultivo áreas más grandes que en la etapa anterior, comercializándose la producción adicional. Además, se puede presentar una diversificación hacia actividades de mayor valor que requieren inversión, tales como la ganadería de doble propósito (Loker 1993) y el establecimiento de cultivos perennes (Brodie et al. 1997), practicadas por agricultores relativamente más acomodados y particularmente aquellos con mayor seguridad de la tierra.

Brodie et al. (1997) ofrecen un análisis del manejo de recursos arbóreos en fincas de pequeños agricultores en Pucallpa, Perú, en un área que probablemente pueda ser clasificada como economía de mercados emergentes. En esta se sigue una estrategia de barbechos de periodo variado, como en la etapa anterior. El manejo de árboles es por lo común extensivo (por ejemplo, limpieza de malezas cada uno o dos años, transplante de plántulas de regeneración) y es básicamente para árboles frutales y maderables que se usan para el consumo y que podrían comercializar. La producción de madera es considerada como una opción futura. Esta suele hacerse en función de la regeneración natural que surge en tierras usadas para cultivos con barbechos de larga rotación, mientras que los árboles maderables maduran. Sin embargo, los autores enfati- zan que la comercialización de árboles es rara. Esto es consistente con un estudio de pequeñas fincas en Altamira, Pará (Walker et al. 1993), que muestra que hay poca madera de alto valor en las fincas y que la madera es vendida sólo ocasionalmente para satisfacer necesidades especiales, debido a los bajos precios. Tanto en Pucallpa como en Altamira, cuando la madera es vendida, los agricultores a menudo reciben el pago en especie. Además del uso comercial, los bosques secundarios sirven también importantes necesidades de subsistencia, principalmente como fuente de leña y postes para construcción (Brodie et al. 1997).

Datos de una encuesta a 214 agricultores en Pucallpa, Perú, aplicando el método de valorización contingente muestran que, si bien los agricultores valoran los bosques principalmente como una fuente de materiales de construcción $(36 \%$ de los encuestados) y de productos forestales no maderables - tales como carne animal, plantas medicinales y leña - $(27 \%$ de los agricultores), se encuentra también que estos valoran los bosques por ciertos beneficios relacionados con el estilo de vida, tales como la purificación del aire $(24 \%$ a $45 \%)$ y la provisión de sombra ( $8 \%$ a $22 \%)$. El estudio determinó que los agricultores estaban dispuestos a dejar de percibir aproximadamente un tercio de su ingreso de la actividad agrícola por el hecho de contar con estos servicios ambientales (Smith et al. 1997) y que, a mayor área deforestada, mayor es el valor atribuído a estos servicios ambientales. Estos valores no económicos también pueden conducir a la preservación de los bosques secundarios.

Datos sobre la existencia de bosques secundarios están empezando a aparecer. Scatena et al. (1996), en una encuesta a 65 agricultores cerca a Santarém, Brasil, con un tamaño promedio de parcela de 88 ha, muestran que los agricultores identifican y usan cinco tipos diferentes de vegetación de barbecho: bosque maduro mayor de 20 años, vegetación secundaria de 8 a 12 años de edad, vegetación secundaria joven de 3 a 6 años, vegetación arbustiva de 2 a 4 años y vegetación herbácea de menos de 2 años de edad. Sin embargo, no se identifica la etapa de intensificación de estos agricultores. Otros autores que documentan la existencia de bosques secundarios en pequeñas propiedades son Witcover y Vosti (1995), quienes encontraron 7\% de la tierra en bosque secundario en Acre, Brasil. Toniolo y Uhl (1995) indican que 24\% del área estaba bajo bosque secundario en Paragominas. Riesco (en Toledo 1992) menciona $17 \%$ en bosque secundario en Pucallpa, Perú y Toledo et al. (1989) encontró también un $17 \%$ en Caquetá, Colombia.

Estos datos parecen indicar que, contrario a la percepción popular, los bosques secundarios existen en pequeñas propiedades. En la etapa de mercados emergentes este recurso puede ser de importancia para los agricultores como fuente de productos para consumo y, de ser posible, de ingresos de dinero; además, hay indicaciones de que los servicios ambientales empezarían 
también a ser considerados (Smith et al. 1997). El manejo extensivo de árboles parece ocurrir a través de todo el ciclo cultivo/barbecho en áreas destinadas para barbechos largos.

Se conoce muy poco sobre la intensidad del uso anterior de la tierra en bosques secundarios, aunque resultados de Walker y Homma (1996) implican que áreas con barbechos largos son relativamente infértiles o ya han sido cultivadas por periodos largos. Asiismo, se conoce muy poco sobre la localización de los bosques secundarios en relación a los bosques primarios.

Una relativa mayor degradación de la tierra y una menor disponibilidad de fuentes cercanas de semillas de especies del bosque alto reduciría en general el potencial ecológico y económico de bosques secundarios en esta etapa, si bien esto también dependería de la existencia de condiciones particulares de sitio y de prácticas de conservación (como dejar ciertos árboles del bosque remanente).

En áreas donde existen incentivos para la ganadería, los primeros colonos convierten tierras a pasturas y las venden a los grandes ganaderos en la etapa de mercados emergentes, resultando en altos niveles de concentración en la propiedad de la tierra. A medida que las pasturas son progresivamente infestadas con malezas, muchas son abandonadas, dando lugar a bosques secundarios. Esto puede llevar al surgimiento de áreas extensas de bosque secundario. En un estudio en Paragominas, Pará, Almeida y Uhl (1995) muestran que en 1988 el área bajo bosques secundarios jóvenes (263,000 ha) fue de cerca del 75\% del área dedicada a la ganadería y la agricultura. En El Petén, Guatemala, los ganaderos que enfrentan problemas de degradación de pasturas (o por otras razones) abandonan las pasturas y las dejan como barbecho por unos cuantos años antes de quemarlos para empezar nuevamente (Kaimowitz 1995). Aunque el capital no es escaso para ellos, en esta situación los ganaderos pueden no estar dispuestos a invertir en bosques secundarios, ya que su propósito principal es la especulación de la tierra, antes que la producción. Lo más probable es que los bosques secundarios estén en tierras relativamente degradadas $\mathrm{y}$, como en la etapa más temprana, distantes de los bosques primarios. Nuevamente, no se sabe si se usan o no productos forestales de los bosques secundarios.

Etapa de la frontera vieja (o frontera en cierre). En esta etapa las fincas virtualmente no tienen más bosque primario y nuevas tierras disponibles para la colonización son cada vez más remotas. Debido a la escasez de tierra, los agricultores buscan aumentar el retorno económico a la tierra. Como resultado, los periodos de barbecho declinan progresivamente, aunque pueden mantenerse algunas áreas de barbecho más largo debido a ciertas características de suelo o topográficas. Esta es la etapa cuando la "crisis del barbecho" puede ocurrir, vale decir, a los pequeños propi- etarios pueden faltarles tierra que ha estado en descanso un tiempo suficientemente largo como para dar retornos viables a la tierra y la mano de obra. En dicha situación, estos pueden decidir vender y como resultado generar en concentración de la tierra, dominancia de pasturas y algún tipo de agricultura mecanizada (Richards 1996). Bajo este escenario esperaríamos muy poco bosque secundario, excepto en áreas inapropiadas para otros usos (SHIFT Project 1993, 1995). Es probable que el bosque secundario desarrollado en pasturas abandonadas en la etapa anterior se tale y se use el producto de las ventas de madera para reconvertir tales tierras a pasturas. Así, mientras que habría muy poco de bosque secundario, este puede servir para generar ingresos monetarios, dado que el costo de restauración de la pastura es alto (por ejemplo, unos \$260/ha en Paragominas, Pará - Mattos y Uhl 1994). Fincas de gran escala probablemente sean cultivadas de forma permanente con cultivos anuales, o se establecen plantaciones de una sola especie.

Sin embargo, Thiele (1995) muestra que la concentración de la tierra no es inevitable, en la ausencia de incentivos gubernamentales para la agricultura de gran escala. La reforma agraria y la legalización de la tenencia de la tierra en parcelas de pequeños propietarios también han apoyado a que persista el sector de pequeña escala. Algunas veces los pequeños propietarios han mantenido la viabilidad de la agricultura invirtiendo en herbicidas o a través de la preparación mecanizada de la tierra. Aquellos que han acumulado capital también han evitado la "crisis del barbecho" invirtiendo en usos de la tierra de alto valor, tales como cultivos perennes y ganadería de doble propósito. En tales situaciones, esperaríamos reducciones sustanciales en bosques secundarios, porque los retornos respecto a otros usos de la tierra probablemente sean más bajos, al menos en el mediano plazo. No obstante, algunos "parches" o "bolsones" de bosque podrían sobrevivir, ya sea debido a que la tierra es inapropiada para otros usos, o por estrategias de diversificación, o bien por motivos no económicos. Sin embargo, es muy probable que los bosques secundarios estén altamente fragmentados.

En términos ecológicos, el efecto combinado de una mayor degradación de los suelos (en las áreas de uso agrícola y a nivel del paisaje en general) y ciertas prácticas de manejo agrícola y/o pecuario, en especial las quemas, reducen considerablemente el potencial ecológico y económico del bosque secundario. En estas condiciones, el proceso sucesional es muy lento y pasa por un periodo relativamente largo en forma de una cubierta dominada por especies herbáceas y/o arbustivas, en gran medida provenientes de material vegetativo (rebrotes, raíces, rizomas). Sin duda, las opciones de manejo se reducen considerablemente y con frecuencia se debe recurrir a la introducción de especies capaces de adaptarse a condiciones de suelos degradados. 


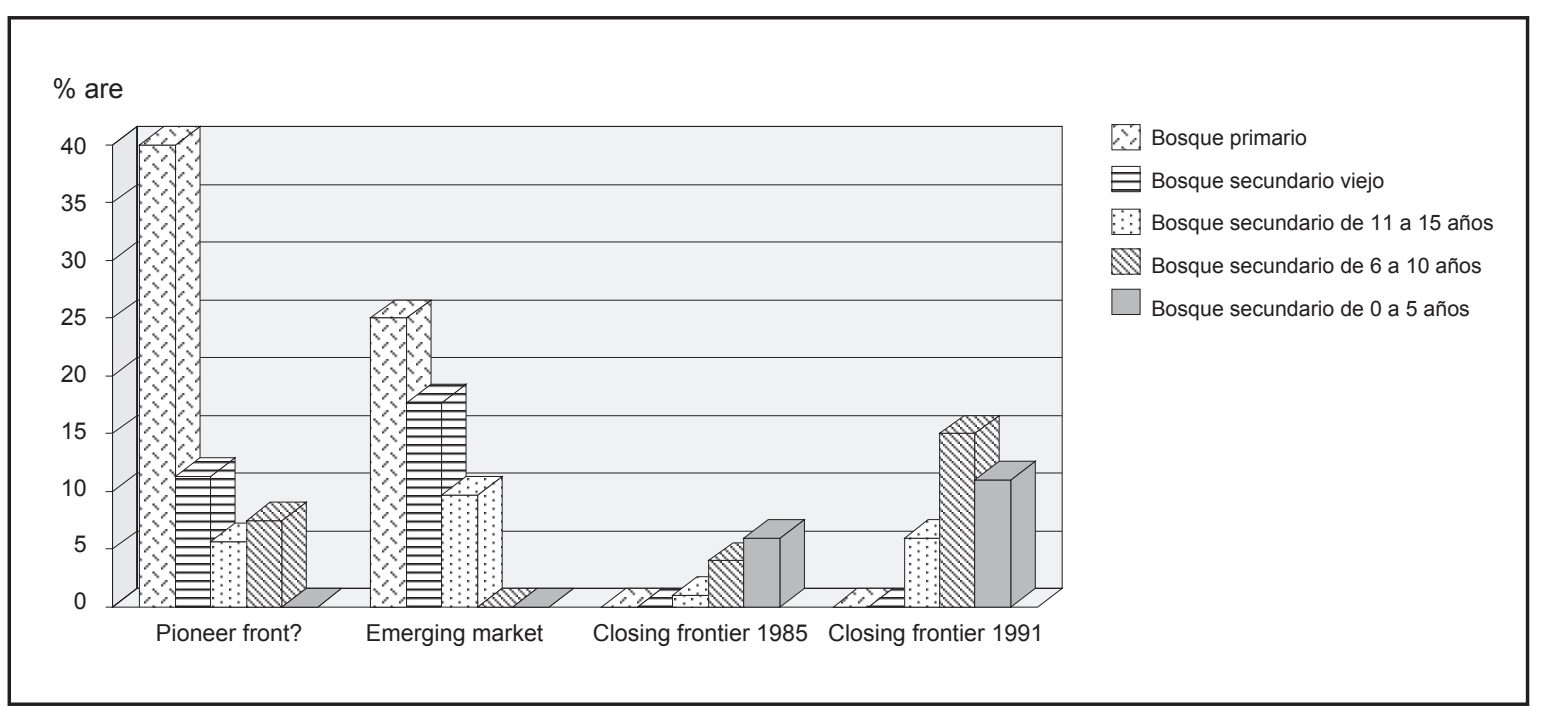

Figura 1. Areas en bosque secundario según etapa de intensificación. (Fuente: Morán et al. 1992 y 1996)

\section{Extensión del bosque secundario y etapas de intensificación}

Aunque empieza a disponerse de más datos sobre la existencia de bosques secundarios a nivel de pequeñas y grandes propiedades, la mayor parte es de naturaleza estática. Resulta difícil saber cómo el área bajo bosque secundario cambia a nivel de finca o de paisaje en las distintas etapas de intensificación. Algunas indicaciones al respecto están siendo disponibles a través de datos de satélite recogidos para la Amazonía oriental en Brasil (Morán et al. 1992 y Morán et al. 1996). La Figura 1 permite apreciar que el bosque primario disminuye de un $40 \%$ a un $25 \%$ del área cubierta por las imágenes, mientras que la proporción de bosque secundario de más de 10 años de edad aumenta de un 16\% a un $26 \%$. En fronteras viejas, donde virtualmente ya no hay más bosque primario, la proporción en esta clase de edad declina fuertemente y la proporción de vegetación secundaria muy joven aumenta. Sin embargo, los datos parecen indicar que dentro de la frontera vieja todas las clases de vegetación secundaria aumentan con el tiempo. Con esto, no hay claridad sobre la existencia de patrones, ni sabemos si los datos son de áreas comparables, o si corresponden a las etapas de intensificación descritas arriba. Ciertamente, se requiere de mayor documentación sobre la interacción entre intensificación y cambios en la extensión y el rol de los bosques secundarios.

\section{Trayectoria de productores indígenas}

Los pequeños productores indígenas en áreas remotas adonde inmigraron por lo general hace ya mucho tiempo y suelen practicar actividades de subsistencia en el bosque, a través de las cuales obtienen una gran variedad de recursos para su uso diario. Al momento que empiezan a practicar agricultura, necesitan tumbar un área de bosque, ya que de otro modo no consiguen crear oportunidades para producir los cultivos suficientes para su alimentacion. El proceso de formación y especialmente de reconversión de bosques secundarios es distinto en el caso de agricultores en áreas que no son parte de un tipo de frontera agrícola. Son agricultores que viven en zonas remotas del bosque tropical, en lugares donde muchas veces solamente se puede llegar por medio de los ríos. En la mayoría de casos, se trata de pobladores indígenas o quasi etnias, como les llama Chibnik (1991) refiriéndose por ejemplo a los ribereños en Perú o los caboclos en Brasil. En donde estos agricultores practican agricultura en tierra firme, las caracteríticas del medio ambiente y la tecnología disponible imponen que el uso de la tierra sea de un periodo de cultivo corto, de uno a cuatro años como máximo, seguido por un periodo en que se deja el cultivo de anuales o semi-perennes. Este tipo de uso se puede ver como una secuencia de agricultura intensiva, seguida por algunos años de uso extensivo, ya que los mismos campos agrícolas todavía se mantienen como un recurso económico lo suficientemente importante.

En la fase de uso extensivo, se desarrolla una vegetación secundaria que tiene como función la recuperación de la biomasa y que, con el tiempo, puede ser cortada y quemada para dar otra vez fertilidad al suelo en el siguente cultivo. El bosque secundario es por lo tanto un componente importante en la agricultura de estos grupos. Este esquema básico, sin embargo, es muy variable según las condiciones del agricultor y el lugar donde vive. Se puede distinguir también un tipo de evolución del sistema de uso de la tierra, pero es 
Cuadro 4. Características de productores indígenas según el estado de intensificación.

\begin{tabular}{|l|l|l|l|}
\hline \multicolumn{1}{|c|}{ Tipo de productor } & \multicolumn{1}{|c|}{ Migratorio } & \multicolumn{1}{|c|}{ Semi-sedentario } & Con acceso al mercado \\
\hline Objetivos generales & Consumo casero & $\begin{array}{l}\text { Consumo casero y } \\
\text { comercialización }\end{array}$ & $\begin{array}{l}\text { Consumo casero y } \\
\text { comercialización }\end{array}$ \\
\hline Recursos & $\begin{array}{l}\text { Mano de obra familiar. } \\
\text { Ningún uso de capital }\end{array}$ & $\begin{array}{l}\text { Mano de obra familar. } \\
\text { Poco uso de capital }\end{array}$ & $\begin{array}{l}\text { Mano de obra familiar } \\
\text { o a veces contratada. } \\
\text { Poco uso de capital }\end{array}$ \\
\hline Acceso al mercado & Casi ausente \\
Ae la tierra y tenencia & $\begin{array}{l}\text { Buen acceso a la tierra. } \\
\text { Tenencia de la tierra es } \\
\text { de poca importancia }\end{array}$ & $\begin{array}{l}\text { Acceso a la tierra es } \\
\text { más restingido. Tenencia de } \\
\text { la tierra es poco definida }\end{array}$ & $\begin{array}{l}\text { Accesso a la tierra es reducida. } \\
\text { Tenencia de la tierra es } \\
\text { insegura y con frecuencia } \\
\text { problemática }\end{array}$ \\
\hline Producción & $\begin{array}{l}\text { Agricultura para } \\
\text { autoconsumo }\end{array}$ & $\begin{array}{l}\text { Agricultura para auto- } \\
\text { consumo, incidentalmente } \\
\text { con producción dirigida hacia } \\
\text { el mercado. Con frecuencia } \\
\text { hay extracción forestal para } \\
\text { el mercado }\end{array}$ & $\begin{array}{l}\text { Agricultura para autoconsumo } \\
\text { combinada con producción } \\
\text { para el merrcado. A veces } \\
\text { hay producción de ganado }\end{array}$ \\
\hline
\end{tabular}

mayormente relacionado con el tipo de asentamiento donde vive el agricultor.

En base a nuestras experiencias de investigación en Perú y en la literatura disponible, podemos reconstruir las siguentes tres diferentes fases evolucionarias de agricultura y manejo de barbechos entre agricultores que mayormente trabajan en zonas interfuviales. Estas son relativamente aisladas y con escasa inmigración, o sea, que no son áreas como las del tipo frontera agricola. La situación es diferente especialmente en aquellas zonas donde los agricultores tienen a la vez accesso a terreno interfluvial e inundable (varzea), pero estos casos no se discutirán aquí.

Agricultura migratoria. Esta primera fase se da en condiciones donde la tierra se usa para agricultura por 1 a 4 años, seguido por un "descanso" por un periodo largo en el que se desarrolla un bosque secundario de edades avanzadas. Esta situación se daría solamente en casos de baja presión demográfica, donde los agricultores practican aún algún tipo de agricultura realmente migratoria. Este tipo de agricultura es típica para grupos étnicos que vivían casi totalmente aislados, aunque actualmente es posible todavía encontrar algunos grupos indígenas que tienen muy poco contacto con la sociedad más amplia en los países donde viven. Sus hogares, o bien las comunidades enteras, son trasladados con una cierta frecuencia. Los asentamientos de algunas casas son rodeadas por áreas de cultivo y áreas de bosque secundario en varios estados de desarollo.
En estas situaciones, hay poco intercambio comercial con el mundo exterior y, si lo hay, es mayormente con productos forestales (Cuadro 4). La limitante principal para vender productos es el transporte. La producción es lograda enteramente usando mano de obra familiar y solamente existen prácticas de intercambio de mano de obra entre familias en forma de minga, que es un intercambio de trabajo donde se invita a familiares, vecinos y amigos y el pago es con comida y bebida. La tenencia de la tierra es poco definida en estos casos, pero los conflictos sobre la propiedad de la tierra son escasos. Parte del área donde se hizo agricultura puede haber sido sembrada con especies perennes, como frutales, pero también con otras especies utiles. Es costumbre que cuando el grupo traslada su hogar, los lugares anteriores de asentamiento son visitados en épocas cuando los frutales producen frutas, o para ir de caza. De otro lado, el bosque secundario poco o no intervenido también es una fuente importante de recursos forestales, como por ejemplo para leña, madera de construcción, plantas medicinales, frutos silvestres, o como lugar de caza (por ejemplo, Denevan y Padoch 1988; Irvine 1987, 1989).

Los agricultores migratorios manejan el bosque secundario o barbecho forestal aún de manera muy extensiva (Balée y Gely 1989; Alcorn 1990), presentándose diferencias entre grupos en la forma como se hace este manejo. Es común sembrar algunos árboles de especies domesticadas, semi-domesticadas, o inclu- 
Cuadro 5. Características de bosques secundarios en parcelas de productores indígenas, según el estado de intensificación.

\begin{tabular}{|l|l|l|l|}
\hline \multicolumn{1}{|c|}{ Tipo de productor } & \multicolumn{1}{|c|}{ Migratorio } & \multicolumn{1}{c|}{ Semi-sedentario } & Con acceso al mercado \\
\hline Edad & Avanzada & $\begin{array}{l}\text { Variado y mixto. Aumenta la } \\
\text { proporción de barbechos } \\
\text { jóvenes }\end{array}$ & $\begin{array}{l}\text { Solamente barbechos } \\
\text { manejados tienen edad } \\
\text { avanzada. Barbechos sin } \\
\text { manejo son muy jóvenes }\end{array}$ \\
\hline Razón & $\begin{array}{l}\text { Recuperación de fertilidad } \\
\text { yroducción de productos } \\
\text { arbóreos }\end{array}$ & $\begin{array}{l}\text { Combinación como en la fase } \\
\text { anterior, pero se inicia una } \\
\text { cierta especia-lización de } \\
\text { barbechos para productos } \\
\text { arbóreos }\end{array}$ & $\begin{array}{l}\text { Recuperación de la fertilidad } \\
\text { yroducción de especies } \\
\text { arbóreas en campos separados }\end{array}$ \\
\hline Uso de productos & Consumo casero & $\begin{array}{l}\text { Consumo casero y } \\
\text { comercialización }\end{array}$ & $\begin{array}{l}\text { Comercialización y consumo } \\
\text { casero }\end{array}$ \\
\hline $\begin{array}{l}\text { Manejo } \\
\text { Cercanía al bosque } \\
\text { primario }\end{array}$ & Próximos & $\begin{array}{l}\text { Algunos barbechos son poco } \\
\text { manejados }\end{array}$ & $\begin{array}{l}\text { Algunos barbechos son } \\
\text { por algunos productores }\end{array}$ \\
\hline
\end{tabular}

so especies forestales, cuando todavía se está cultivando anuales o semi-perennes en el campo agrícola. También en esta fase es muy común empezar a proteger individuos de especies que son típicas de bosques secundarios. Muchas de las especies arbóreas sembradas o protegidas en los primeros años recién empezarán a producir, o podrán ser utilizadas, cuando la vegetación a su alrededor ya se ha desarrollado en un barbecho forestal de edad avanzada. Sin embargo, entre estos tipos de agricultores es poco común practicar limpiezas en barbechos fuera de los frutales alrededor de la casa (Cuadro 5).

Semi sedentarismo. Una ocasión importante para el cambio es cuando llegan servicios tales como la educación formal y se construye una escuela o instituciones de servicios; entonces, muchos agricultores se vuelven más o menos sedentarios. Los agricultores producen para autoconsumo, pero crecientemente también para la venta en el mercado. En muchos casos, los ingresos financieros no provienen de la agricultura, sino de la venta de productos forestales. La tenencia de la tierra es más definida, aunque todavía puede ser fácilmente transferida, por ejemplo cuando el dueño de un lugar abandona el asentamiento (Cuadro 4).

En esta fase, la distancia desde la comunidad o desde la casa hacia los campos agrícolas empieza a ser un factor de importancia en la toma de decisiones agrícolas. Ello tiene un impacto importante sobre el ciclo agrícola y el tiempo que se deja desarrollar un barbe- cho antes de usar el lugar nuevamente para la producción agrícola intensiva. En estas condiciones, por lo general continúa el avance en la conversión del bosque primario para crear nuevas tierras agrícolas, pero a la vez aumenta la frecuencia de uso agrícola en los campos próximos al centro de la comunidad. El resultado es un mosaico de bosques secundarios en diferentes estados de desarrollo y con una historia de uso de la tierra muy variable. En general, las fincas son relativamente pequeñas y los productores tienen de uno a tres campos con sembríos agricolas, estando los demás lugares bajo alguna vegetación arbórea, sea como huertos frutales, o bien como barbechos forestales.

En estos mismos casos, la importancia económica de bosques secundarios aumenta, principalmente porque poco a poco reemplazan al bosque primario como fuente de productos forestales, ya que este último se encuentra cada vez más distante. El beneficio económico que pueden dar los bosques secundarios, unido a la relativa facilidad con que estos pueden responder a la intervención humana, explican por qué los pequeños agricultores empiezan a manejar sus barbechos forestales. En este sentido, los barbechos son principalmente diferentes al bosque primario (residual o no), donde también se pueden encontrar muchas especies útiles, pero donde se reducen las opciones para cambiar la composición o la estructura a fin de aumentar los beneficios materiales.

Existen varios estudios que demuestran la importancia económica de los barbechos en la economía de 
estos pequeños productores como fuente de productos para el consumo hogareño $\mathrm{y}$, en menor medida, para obtener ingresos de dinero (Padoch 1987; Denevan y Padoch 1988; Padoch y de Jong 1989). Muchos productores en estas condiciones también siembran especies arbóreas en sus campos agrícolas, las que luego se desarrollan en conjunto con el resto de vegetación (Cuadro 5). La intensidad del cuidado de estos árboles, una vez que se dejan de producir cultivos netamente agrícolas, es muy variable. Pueden existir como parte de un barbecho sin intervención, como también se dan casos en que los agricultores realizan limpiezas alrededor de individuos de especies útiles que han surgido espontáneamente (de Jong 1995). Asimismo, se conocen casos donde los agricultores ya desde un inicio permiten que en su campo agrícola se regeneren algunas especies propias del bosque secundario. Fuera de las condiciones biofísicas, la historia de uso de la tierra y la distancia al bosque primario, la siembra de especies arbóreas y las labores de limpieza son los dos factores más importantes que influyen en el desarrollo de un barbecho forestal.

Cuando el bosque secundario ya está bien desarrollado, el dueño puede aplicar diferentes intensidades de intervención: cosechar productos cuando los necesita o cuando es época de maduración, hacer limpiezas o deshierbos (sólo para librar algunos individuos del bosque secundario o de especies domesticadas, o bien aplicadas sobre parte o la totalidad del barbecho). Además, la atención que el agricultor da a su o sus barbechos puede variar mucho de año a año (Alcorn 1990).

Como los bosques secundarios de barbechos son los más desarrollados entre agricultores de tipo migratorio o semi-sedentario, desde el punto de visto ecológico estos bosques tienen el potencial más alto para generar productos destinados a la venta. Sin embargo, el difícil acceso a los mercados desde los lugares donde se encuentran requiere que cualquier producto comercializado deba tener un valor relativo muy alto por volumen y peso. Esto podría darse con productos como carbón producido en base a especies del bosque secundario, fibras de palmeras para uso en artesanía, ciertas plantas medicinales (p.e. Ficus elastica o Uncaria tomentosa en el caso de Perú) u otros productos con valor relativamente alto, o bien que pueden obtener un valor agregado dentro del área donde son cosechados. Productos como madera solamente podrán ser de interés cuando se trata de especies de valor comercial alto, o cuando se puede producir madera en dimensiones que se puedan aserrar en el lugar mismo de producción.

Acceso al mercado. Cuando aumenta el contacto con centros urbanos, empiezan a producirse cambios en las prácticas agrícolas de los pequeños agricultores que no fueron parte de la migración hacia una frontera agrícola. Esto generalmente sucede cuando los centros urbanos se expanden en la cercanía de pueblos que anteriormente estaban aislados. Si el contacto es por medio de carreteras, la situación tiende a ser casi similar a lo que sucede en una frontera agrícola. Como ya se ha desarrollado una agricultura extensiva en el lugar que recién está en contacto con el centro urbano, este inmediatamente entra en una fase que es parecida a la de economía de mercado emergente en el caso de una frontera agricola, como se ha descrito en páginas anteriores.

Un aumento de intercambio con centros urbanos también puede ocurrir con pueblos que no están conectados por carretera sino por río, en cuyo caso la evolución es diferente. Aquí, los agricultores generalmente aumentan su producción agrícola para vender una parte importante de su cosecha en el mercado. Sin embargo, también pueden dedicar más atención a una producción comercial, por ejemplo, usando recursos de sus barbechos, los que entonces se pueden convertir en un tipo de arboricultura (Padoch et al. 1985). En estos casos, por lo general se observa un manejo intensificado, aunque este es aplicado por algunos y no todos los agricultores y solamente en algunos de sus barbechos y no en todos (de Jong 1995). Puede darse el caso también que otros agricultores empiecen con la producción de ganado.

En estas condiciones, hay una clara intensificación de uso de algunos bosques secundarios, pero un uso poco intensivo en otros. En los barbechos que no son manejados en forma intensiva, el ciclo de agricultura intensiva se repite cada vez con más frecuencia. La tenencia de la tierra se vuelve muy estricta y los conflictos por la tierra también son más frecuentes (Cuadros 4 y 5).

Las opciones de manejo para bosques secundarios son mayores en estas condiciones, siempre y cuando exista un mercado para los productos que se pueden producir, especialmente en lugares donde ya se ha practicado agricultura por un cierto tiempo. Sin embargo, el manejo del bosque secundario para obtener ingresos tiene que producir una mínima utilidad al agricultor, de lo contrario, resultará para este más conveniente el trasladarse hacia el centro urbano o hacia otro lugar.

\section{Dueños "accidentales", "paralizados" o "indiferentes"}

Un porcentaje importante del bosque secundario existente es resultado de fincas o parcelas que han sido abandonadas por diversas razones. Estos bosques pueden ocurrir en cualquier etapa de intensificación en las márgenes de bosque y pueden incluir:

- fincas bajo litigio o que han sido retomadas por la banca por falta de pago;

- explotaciones donde los dueños han muerto y los herederos no tienen interés en trabajar la finca, 
pero tampoco pueden ponerse de acuerdo para vender;

- propiedades donde los dueños son demasiado viejos o enfermos para trabajar sus tierras, o donde hay muy poca mano de obra familiar disponible;

- tierras que han sido compradas por familias urbanas con fines de recreo o de especulación; y

- fincas que han sido abandonadas por problemas de secuestro, asaltos y conflictos militares.

Datos de INTECFOR (1993) muestran que Nicaragua tendría actualmente $1.1 \mathrm{mill}$. ha de 'bosque arbustivo' (definido como áreas donde predominan especies leñosas de menos de $5 \mathrm{~m}$ de altura) y 900,000 ha adicionales en 'barbecho forestal' (definido como vegetación leñosa que aparece después del aclareo del bosque natural para la agricultura migratoria). Muchas de estas áreas probablemente revirtieron de pasturas y cultivos a bosque secundario durante el periodo 19831989 como resultado de los conflictos militares. En 1991, Guatemala tenía alrededor de 360,000 ha de bosque secundario (Cabrera 1992). El conflicto militar durante los años 1980 habría sido un factor importante para que los cultivos y pasturas hayan sido abandonados a bosque secundario en el norte de Guatemala. Situaciones similares se habrían producido también en algunas zonas amazónicas de Perú y Colombia, pero no se conoce de datos que documenten estos cambios.

Lo que todas estas situaciones tienen en común es que hay muy pocas probabilidades de que el dueño (si es que lo hubiese) tenga interés en el manejo del bosque secundario. Justamente el abandono es un reflejo del bajo nivel de capacidad y/o interés en realizar cualquier tipo de manejo de esas tierras.

A manera de resumen, el análisis de procesos socioeconómicos (Cuadros 2, 3, 4, 5) muestra que las áreas, características y funciones de los bosques secundarios varían ampliamente según las diferentes trayectorias de intensificación. Dichos cuadros ilustran que, a través del tiempo, los propietarios de bosques secundarios pueden pasar de una etapa de intensificación a la otra, resultando en cambios en sus objetivos y sus recursos. El análisis muestra que las funciones y el potencial de bosques secundarios pueden cambiar a través del tiempo mientras que sus propietarios pasen de una etapa de intensificación a la otra, cambiando así sus recursos y objetivos. De esta manera, las estrategias para viabilizar el potencial de los bosques secundarios se deben basar también en una perspectiva dinámica. El area en bosques secundarios y sus caracteristicas esta estrechamente relacionado con actividades agropecuarias. Esto indica la importancia de analisar bosques secundarios como parte integral del sistema total de uso de la tierra de sus propietarios.

\section{OPCIONES DE MANEJO}

\section{Enfoque central}

En el marco de este documento, nuestro enfoque principal es hacia el bosque secundario como un recurso renovable capaz de contribuir a generar ingresos sostenidos a las poblaciones rurales en zonas de frontera agrícola, al mismo tiempo que se mantienen o mejoran los servicios ambientales y beneficios sociales que se derivan de su conservación. Este enfoque también considera que para una amplia proporción de los productores rurales, una razón importante de dejar bosques secundarios es su función para recuperar la productividad de la tierra para uso agrícola o de diversificar sus actividades. De otro lado, se puede ver al bosque secundario como una oportunidad para generar mayor valor agregado a la producción primaria (por ejemplo, para el desarrollo de la agroindustria y de industrias forestales), creando con ello un efecto multiplicador en las economías locales y regionales.

La implementación de sistemas alternativos de uso de la tierra y tecnologías para contener la deforestación debe estar basada en criterios de sostenibilidad aplicados en sus diferentes dimensiones: ecológica, económica y socio-cultural. Como menciona Serrâo (1994): "El análisis de sostenibilidad de sistemas de uso de la tierra agrícolas y forestales debe tomar en cuenta la importancia presente y potencial de su escala de utilización (área total usada y número de agricultores involucrados), tipos de usuarios de cada sistema, su importancia económica, las posibilidades para mercados futuros, las implicaciones ambientales y las posibilidades para agroindustrias." Esta aserción indica, por un lado, la estrecha relación entre ambos sistemas de uso a nivel de la parcela o finca, en donde pueden darse oportunidades de complementaridad (alimentos, productos forestales, protección ambiental, comercialización) u otras de conflicto (competencia por la tierra, malezas y plagas, daños por aprovechamiento). De otro lado, sugiere un elemento de planificación a un nivel mayor a la parcela, que dependerá del contexto socio-cultural, económico y de políticas.

\section{Objetivos del productor}

El o los objetivos que establece el productor o dueño sobre la retención y manejo del bosque secundario en su parcela o terreno están generalmente en función a sus necesidades, intereses, expectativas y capacidades. Con el fin de discutir las opciones de manejo y las tecnologías posibles de implementar, se proponen tentativamente los siguientes objetivos principales del productor para conservar y/o manipular bosques secundarios:

- Aumentar la capacidad de recuperación de la productividad de los suelos para uso agrícola. La idea 
central es acortar el periodo de descanso, reducir malezas, etc. El sistema de uso resultante sería un barbecho (agrícola) "mejorado" de ciclo corto.

- Diversificar los productos que se pueden obtener del bosque secundario (como fuente de alimentación, medicinas, madera utilitaria, combustible, etc., tanto para consumo directo y/o la venta). El productor busca reducir su dependencia del mercado y, si es posible, generar pequeños ingresos adicionales. El sistema resultante sería un barbecho (forestal) de ciclo mediano a largo.

- Aumentar la productividad y el valor comercial del bosque secundario para generar ingresos a través de la venta de productos forestales, maderables y no maderables. El paso progresivo hacia una economía de mercado podría incentivar al productor a aumentar las áreas bajo bosque secundario bajo manejo forestal, especialmente si en paralelo se desarrolla un eficiente sistema de procesamiento y comercialización. Aquí se puede hablar de un sistema de manejo del bosque para producción forestal comercial.

- Asegurar la permanencia del bosque, principalmente por sus funciones de protección, ambientales y de recreación, al tiempo que constituye una especie de reserva (de tierras y/o de productos que podría vender). La referencia podría ser hecha como bosque en conservación o reserva.

Además de que un productor dado decida tener uno o más objetivos, este puede asignarles diferentes grados de importancia o prioridad, pudiendo también variar en el tiempo, como parte del proceso de intensificación del uso de la tierra y el desarrollo del contexto socioeconómico y de políticas.

\section{Opciones tecnológicas para el manejo}

Asumiendo que los objetivos anteriores son válidos, esto es, responden a las necesidades, intereses, expectativas y capacidades del productor, podría esperarse que uno o más de estos objetivos puedan combinarse en el espacio y/o el tiempo. Nótese que cada objetivo estaría representando en realidad una opción de manejo, lo que querría decir que un productor podría decidirse por tener en su propiedad áreas en barbecho de corta duración, otras con barbechos (multi-propósito) en ciclos largos y quizá bosques destinados principalmente a la producción forestal (por ejemplo, para madera con fines de aserrío).

De aquí es posible desarrollar un marco para identificar las opciones tecnológicas que pueden ser adoptadas con mayor probabilidad por un tipo determinado de productor. La adopción de estas posibilidades $\mathrm{u}$ opciones dependerían de variables que pueden actuar como limitantes para el productor, tales como:
- $\quad$ tipo de tenencia

- tamaño del terreno y cuánto de este puede ser utilizado para la producción agrícola y/o pecuaria

- condiciones de sitio (calidad de suelos, pendientes no aptas para agricultura, etc.)

- disponibilidad de mano de obra (en relación con la agricultura y/o ganadería)

- capital disponible

- capacidad gerencial

- acceso al mercadoconocimientos o experiencia previa del productor sobre prácticas (agro-) forestales

- marco político y legal en relación a las actividades de producción forestal

En los cuadros 2 a 5 se presentó una caracterización de los productores en cada etapa de intensificación de acuerdo a estos criterios, excluyendo por ahora los aspectos de política.

Los cuadros 6 y 7 son el resultado de un esfuerzo interdisciplinario que identifica un conjunto de variables para caracterizar las opciones de manejo. Entendemos que estas variables constituyen un punto de partida para desarrollar criterios que puedan ser aplicados a situaciones específicas, las que definitivamente requerirían de la participación directa de los propios usuarios a nivel local.

\section{Integrar los bosques residuales}

Sin duda, las opciones del Cuadro 7 no son completas. Si bien hemos querido circunscribirnos en este trabajo a los bosques secundarios sucesionales o barbechos forestales, en la realidad estos se presentan en las fincas o parcelas de productores junto con bosques primarios residuales en diferente grado de intervención por actividades extractivas (de madera y/o productos diferentes a la madera). En teoría, estos bosque también pueden ser considerados por el productor como parte de sus opciones de producción y/o de conservación (los objetivos planteados anteriormente), aunque en la práctica pueden presentarse limitaciones, como por ejemplo:

- deforestar un bosque residual es más oneroso (toma más tiempo y es más difícil si no se cuenta con motosierra, etc.)

- el marco político-legal para bosques altos generalmente es más restrictivo y está sujeto a mayor control por la administración forestal (por ejemplo, la exigencia a presentar un plan de manejo, o bien un plan de aprovechamiento; reglamentación sobre un área máxima a deforestar por parcela, como sucede en el Brasil) 
Cuadro 6. Variables para la caracterización de opciones de manejo en bosques secundarios. (uente: Proyecto CIFOR/CATIE/BID 1996)

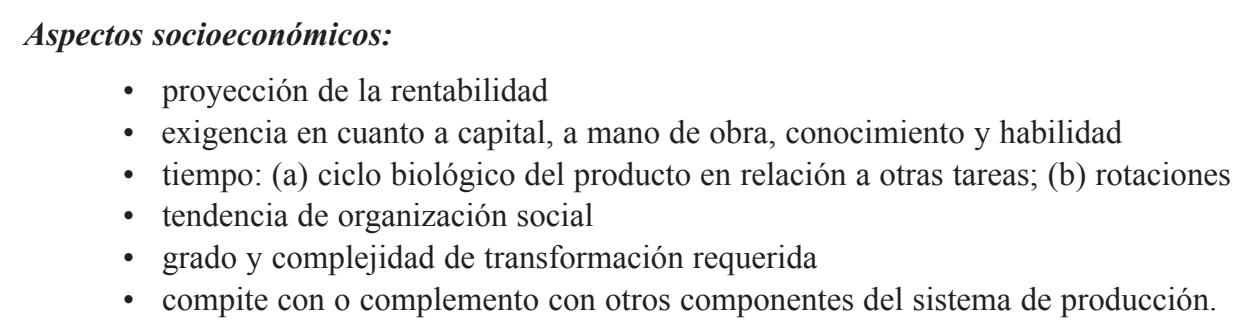

Aspectos biofisicos:

- especies utilizables (maderables y no maderables) presentes, su abundancia y productividad

- especies que pueden ser incorporadas al sistema

- tamaño y dispersión de rodales en la finca y a nivel de paisaje

- efecto de condiciones de sitio sobre opciones de cosecha y extracción

- complejidad de técnicas culturales y de extracción

- complejidad del manejo propuesto con necesidades de protección

- evaluación inicial de posibilidades de sostenibilidad ecológica de la producción

- marco político-legal

- $\quad$ por estar en terrenos menos aparentes para la agricultura y/o ganadería (como pendientes fuertes, áreas sujetas a inundación frecuente, áreas con alta rocosidad, etc.), las opciones productivas son más limitadas

De otro lado, los bosques residuales son potencialmente más interesantes desde el punto de vista de ingresos a más corto plazo, si el productor puede usar o vender la madera comercial que aún queda en el bosque. En este sentido, también abriría posibiliddes para diversificar y/o aumentar los ingresos, de integrarse un procesamiento y la comercialización de productos del bosque. Además, el bosque residual ofrece habitats que pueden ser más preferidos por ciertas especies de fauna cinegética. Asimismo, valores asociados a la biodiversidad, usos múltiples del bosque y la conservación ambiental son comparativamente mayores en bosques residuales que en bosques secundarios sucesionales, aunque esto también dependería del grado de fragmentación del bosque.

De lo anterior, se puede concluir que cualquier planteamiento de integrar la producción forestal a nivel de productores en zonas de frontera agrícola debería incluir, en lo posible, los diferentes tipos de bosque que se presenten o se establezcan en la propiedad; esto sería en buena medida válido también para las plantaciones forestales que el productor decida establecer con fines de producción forestal. Como se indicó en un inicio, restringiremos los análisis siguientes a los bosques secundarios en su sentido estricto (ver sección 2).

\section{Relación entre opciones tecnológicas y características del productor}

En esta sub-sección hacemos una correspondencia entre las características asignadas a las opciones tecnológicas del Cuadro 7 con las características de la tipología de productores en los cuadros 2 a 5 , a fin de dirigir las tecnologías a los productores que más probablemente puedan adoptarlas.

\section{Productores colonos}

Barbecho mejorado de ciclo corto (< 5 años) para la recuperación de la fertilidad del suelo. El Cuadro 3 muestra que la recuperación del suelo es uno de los objetivos de mantener los bosques secundarios para los productores colonos de pequeña escala en las tres etapas de intensificación. Sin embargo, de estos tres grupos, es poco probable que aquellos en la etapa pionera temprana se interesen en invertir recursos para reducir los periodos de barbecho, debido a que tendrían suficiente tierra para hacer posible los barbechos largos. El mayor interés en acortar el periodo de barbecho sería más probable que aparezca en la etapa de frontera vieja, donde la tierra empieza a escasear. Allí, tecnologías tales como el "mulching" y los abonos orgánicos son más aparentes de ser aceptadas que los cultivos de cobertura de leguminosas, que tienen un alto costo de oportunidad de la tierra. Los productores mejor acomodados en la frontera vieja también podrían estar interesados en los sistemas silvopastoriles, dado que estos disponen de niveles algo más altos de capital, mano de obra y capacidad para el manejo. 
Cuadro 7. Caracterización de algunas prácticas y tecnologías disponibles para diferentes objetivos (opciones) de manejo en función de variables críticas para los productores (a nivel de requerimientos de capital, mano de obra y capacidad gerencial, y de uso competitivo de la tierra (versus tierra para agricultura).

\begin{tabular}{|l|c|c|c|c|c|}
\hline $\begin{array}{l}\text { Ejemplos de prácticas y } \\
\text { technologías disponibles }\end{array}$ & Capital & Tierra & $\begin{array}{c}\text { Mano } \\
\text { de obra }\end{array}$ & $\begin{array}{c}\text { Capac. } \\
\text { gerencial }\end{array}$ & $\begin{array}{c}\text { Tiempo de } \\
\text { producción y tipo } \\
\text { de producto }\end{array}$ \\
\hline
\end{tabular}

Sistema de uso: Barbecho mejorado, de ciclo corto $(<5$ años) - Aumentar la eficiencia del barbecho para acelerar la recuperación de la productividad del suelo para fines agrícolas y/o pecuarios

\begin{tabular}{|c|c|c|c|c|c|}
\hline $\begin{array}{l}\text { Introducción de capa verde o muerta } \\
\text { ("mulching") }\end{array}$ & bajo & bajo & bajo & bajo & bajo \\
\hline $\begin{array}{l}\text { Incorporación de cobertura de } \\
\text { leguminosas (especies "regeneradoras") }\end{array}$ & bajo & medio & bajo & bajo & $\begin{array}{l}\text { bajo - semillas para } \\
\text { uso en la finca y/o }\end{array}$ \\
\hline $\begin{array}{l}\text { Utilización de abonos orgánicos } \\
\text { producidos fuera del área (como estiércol } \\
\text { animal, lombrices de tierra) }\end{array}$ & medio & bajo & medio & $\begin{array}{l}\text { la venta } \\
\text { bajo }\end{array}$ & $\begin{array}{l}\text { bajo - abono para } \\
\text { uso en la finca y/o } \\
\text { la venta }\end{array}$ \\
\hline $\begin{array}{l}\text { Manejo de rebrotes de especies "facilita- } \\
\text { doras" de una colonización rápida }\end{array}$ & bajo & medio & medio & bajo & medio \\
\hline $\begin{array}{l}\text { Cultivos en fajas o corredores } \\
\text { (con especies de ciclo corto y semi- } \\
\text { perennes) }\end{array}$ & $\begin{array}{l}\text { bajo a } \\
\text { medio }\end{array}$ & medio & medio & medio & $\begin{array}{l}\text { medio - semillas y/o } \\
\text { material vegetativo } \\
\text { para uso en la finca } \\
\text { y/o la venta }\end{array}$ \\
\hline $\begin{array}{l}\text { Consorcio silvopastoril (especies } \\
\text { arbóreas y forrajeras) }\end{array}$ & medio & medio & medio & medio & $\begin{array}{l}\text { medio - frutos, } \\
\text { madera, resinas, etc. } \\
\text { para uso en la finca }\end{array}$ \\
\hline $\begin{array}{l}\text { Reforma de pasturas (uso de especies } \\
\text { forrajeras mejor adaptadas, aplicación } \\
\text { de fertilizantes y fungicidas, etc) }\end{array}$ & alto & medio? & alto & alto & $\begin{array}{l}\text { medio - aumento de } \\
\text { productividad animal; } \\
\text { menor mantenim.? }\end{array}$ \\
\hline \multicolumn{6}{|c|}{$\begin{array}{l}\text { Sistema de uso: Barbecho mejorado, enriquecido o multi-propósito, de ciclo medio (> 5-10 años) - Aumentar la } \\
\text { disponibilidad de productos útiles para uso en la finca y diversificar la producción }\end{array}$} \\
\hline $\begin{array}{l}\text { Retención de árboles remanentes de } \\
\text { especies que atraen la fauna o } \\
\text { polinizadores, y/o árboles semilleros } \\
\text { de especies interés comercial }\end{array}$ & bajo & bajo & bajo & bajo & $\begin{array}{l}\text { bajo - semillas } \\
\text { (especies de valor } \\
\text { comercial) para uso } \\
\text { en la finca y/o } \\
\text { para la venta }\end{array}$ \\
\hline $\begin{array}{l}\text { Selección y fomento de especies } \\
\text { útiles (maderables y no maderables) } \\
\text { que crecen naturalmente }\end{array}$ & bajo & medio & bajo & bajo & $\begin{array}{l}\text { bajo/medio - madera, } \\
\text { postes, frutos, resi-nas, } \\
\text { medicinas, etc. para } \\
\text { uso en la finca y/o } \\
\text { para la venta }\end{array}$ \\
\hline $\begin{array}{l}\text { Enriquecimiento con especies } \\
\text { perennes de utilidad conocida (para } \\
\text { alimentación, uso en construcción, } \\
\text { medicinales, etc.) }\end{array}$ & medio & medio & medio & medio & $\begin{array}{l}\text { medio a alto - madera } \\
\text { (de valor), postes, } \\
\text { frutos, etc. para uso } \\
\text { en la finca y/o para } \\
\text { la venta }\end{array}$ \\
\hline $\begin{array}{l}\text { Establecimiento de cultivos multiestrato } \\
\text { con especies semi-perennes y } \\
\text { perennes de utilidad conocida }\end{array}$ & $\begin{array}{l}\text { medio a } \\
\text { alto }\end{array}$ & $\begin{array}{l}\text { medio a } \\
\text { alto }\end{array}$ & $\begin{array}{l}\text { medio a } \\
\text { alto }\end{array}$ & $\begin{array}{l}\text { medio a } \\
\text { alto }\end{array}$ & $\begin{array}{l}\text { medio a alto - } \\
\text { alimentos, aceites, } \\
\text { extractivos, medici- } \\
\text { nas, madera, etc. } \\
\text { para uso en la finca } \\
\text { o la venta }\end{array}$ \\
\hline
\end{tabular}


Cuadro 7 continued

\begin{tabular}{|c|c|c|c|c|c|}
\hline $\begin{array}{c}\text { Ejemplos de prácticas y } \\
\text { technologías disponibles }\end{array}$ & Capital & Tierra & $\begin{array}{c}\text { Mano } \\
\text { de obra }\end{array}$ & $\begin{array}{c}\text { Capac. } \\
\text { gerencial }\end{array}$ & $\begin{array}{c}\text { Tiempo de } \\
\text { producción y tipo } \\
\text { de producto }\end{array}$ \\
\hline
\end{tabular}

Sistema de uso: Bosque de producción forestal, ciclo medio a largo (> 8-10 años) - Aumentar la productividad y el valor de productos y servicios del bosque secundario

\begin{tabular}{|c|c|c|c|c|c|}
\hline $\begin{array}{l}\text { Retención y manejo (limpiezas) de } \\
\text { árboles semilleros de especies de valor } \\
\text { comercial }\end{array}$ & bajo & $\begin{array}{l}\text { medio } \\
\text { variable }\end{array}$ & bajo & bajo & $\begin{array}{l}\text { bajo/medio - venta } \\
\text { de semillas / venta de } \\
\text { madera de alto valor }\end{array}$ \\
\hline $\begin{array}{l}\text { Raleos de liberación para favorecer } \\
\text { árboles de especies de interés comercial }\end{array}$ & bajo & alto & medio & $\begin{array}{l}\text { bajo } \\
\text { a medio }\end{array}$ & $\begin{array}{l}\text { medio - uso de } \\
\text { madera y/o postes } \\
\text { en la finca }\end{array}$ \\
\hline $\begin{array}{l}\text { Refinamiento (eliminación de especies } \\
\text { indeseables) para favorecer especies de } \\
\text { interés comercial }\end{array}$ & $\begin{array}{l}\text { medio a } \\
\text { alto }\end{array}$ & alto & alto & medio & $\begin{array}{l}\text { medio - uso de postes } \\
\text { en la finca }\end{array}$ \\
\hline $\begin{array}{l}\text { Limpiezas del sotobosque para favorecer } \\
\text { la regeneración comercial estableciéndose }\end{array}$ & bajo & alto & medio & bajo & alto \\
\hline $\begin{array}{l}\text { Inducción de la regeneración natural com. } \\
\text { a través de la remoción del dosel alto }\end{array}$ & alto & alto & alto & alto & $\begin{array}{l}\text { alto - uso de madera } \\
\text { y/o postes en la finca }\end{array}$ \\
\hline $\begin{array}{l}\text { Exposición del suelo para favorecer la } \\
\text { regeneración comercial }\end{array}$ & bajo & alto & alto & medio & alto \\
\hline $\begin{array}{l}\text { Enriquecimiento con especies forestales } \\
\text { de valor comercial, plantadas en líneas, } \\
\text { grupos o en claros del dosel }\end{array}$ & medio & $\begin{array}{l}\text { alto } \\
\text { medio? }\end{array}$ & medio & medio & alto \\
\hline
\end{tabular}

Sistema de uso: Bosque de conservacion, ciclo largo (>20 años) - Asegurar la permanencia del bosque secundario para fines de protección /conservación y como reserva futura, o para especulación

\begin{tabular}{|l|l|l|l|l|l}
\hline $\begin{array}{l}\text { Reserva (protección) de especies útiles } \\
\text { para la fauna y como árboles semilleros }\end{array}$ & bajo & bajo & bajo & bajo & $\begin{array}{l}\text { bajo - aumento de } \\
\text { fauna, cosecha de } \\
\text { semillas }\end{array}$ \\
$\begin{array}{l}\text { Medidas de protección contra el fuego y } \\
\text { la entrada de ganado }\end{array}$ & bajo/alto & bajo? & medio & bajo & $\begin{array}{l}\text { bajo - aumento de } \\
\text { fauna, cosecha de } \\
\text { semillas y otros } \\
\text { PFNM }\end{array}$ \\
$\begin{array}{l}\text { Colecta de regeneración de especies de } \\
\text { interés para transplante dentro de la finca } \\
\text { (entriquecim. de barbechos y bosque alto) }\end{array}$ & bajo & bajo & medio & medio & $\begin{array}{l}\text { bajo - material vegetal } \\
\text { para uso en la finca }\end{array}$ \\
$\begin{array}{l}\text { Manejo de fauna silvestre } \\
\text { (de interés cinegético) }\end{array}$ & alto? & medio/ & alto & alto & $\begin{array}{l}\text { medio - productos de } \\
\text { la fauna (carne, pieles, } \\
\text { cueros) para consumo } \\
\text { y/o venta }\end{array}$ \\
\hline
\end{tabular}


Los grandes ganaderos en las etapas pionera temprana y de los mercados emergentes estarían interesados principalmente en la especulación de la tierra. Por tanto, es probable que la recuperación de la fertilidad de los suelos no sea importante para ellos. De otro lado, los ganaderos en la frontera vieja estarían más interesados en la renovación de pasturas y tendrían los medios para acceder a los altos niveles de recursos que requieren dichas tecnologías (Cuadro 8).

Barbechos mejorados en ciclos cortos a medios (>5-10 años) para productos de subsistencia $y$ diversificación del ingresos. La eficacia de las tecnologías basadas en la regeneración natural depende de la abun- dancia e uniformidad en la distribución espacial de especies de interés. Si la regeneración de las especies útiles es muy pobre y/o agregada en ciertos sectores y totalmente ausente en otros, se podría optar por recurrir a la plantación de enriquecimiento. Los pequeños productores en la etapa de mercados emergentes son los que probablemente más se interesen por trabajar con la regeneración natural, particularmente en áreas de crecimiento secundario que no han sido usadas intensamente. En las partes más degradadas de sus fincas, podrían preferir optar por el enriquecimiento, pero los requerimientos más altos de recursos de esta práctica podrían implicar que sólo los agricultores mejor establecidos la lleguen a adoptar.

Cuadro 8. Relación entre tecnologías y caracteristicas de los productores "colonos"

\begin{tabular}{|c|c|c|c|c|c|c|}
\hline $\begin{array}{c}\text { Etapa de } \\
\text { intensificación }\end{array}$ & $\begin{array}{c}\text { Pionera } \\
\text { temprana }\end{array}$ & $\begin{array}{l}\text { Pionera } \\
\text { temprana }\end{array}$ & $\begin{array}{l}\text { Mercados } \\
\text { emergentes }\end{array}$ & $\begin{array}{c}\text { Mercados } \\
\text { emergentes }\end{array}$ & $\begin{array}{l}\text { Frontera } \\
\text { vieja }\end{array}$ & $\begin{array}{l}\text { Frontera } \\
\text { vieja }\end{array}$ \\
\hline Tecnología & $\begin{array}{l}\text { Escala } \\
\text { pequeña }\end{array}$ & $\begin{array}{l}\text { Escala } \\
\text { grande }\end{array}$ & $\begin{array}{c}\text { Escala } \\
\text { pequeña }\end{array}$ & $\begin{array}{l}\text { Escala } \\
\text { grande }\end{array}$ & $\begin{array}{c}\text { Escala } \\
\text { pequeña }\end{array}$ & $\begin{array}{l}\text { Escala } \\
\text { grande }\end{array}$ \\
\hline $\begin{array}{l}\text { Barbecho mejorado } \\
(<5 \text { años) para } \\
\text { recuperación de } \\
\text { suelos) }\end{array}$ & & & & & $\begin{array}{l}\text { "Mulch", } \\
\text { abonos } \\
\text { orgánicos. } \\
\text { Sistemas silvo- } \\
\text { pastoriles para } \\
\text { productores } \\
\text { con más } \\
\text { recursos }\end{array}$ & $\begin{array}{l}\text { Recuperación } \\
\text { de pastos }\end{array}$ \\
\hline $\begin{array}{l}\text { Barbecho (> 5-10 } \\
\text { años) para } \\
\text { subsistencia y } \\
\text { recuperación de } \\
\text { suelos) }\end{array}$ & $\begin{array}{l}\text { Regene- } \\
\text { ración } \\
\text { natural }\end{array}$ & & $\begin{array}{l}\text { Regeneración } \\
\text { natural en áreas } \\
\text { menos degrada- } \\
\text { das, cerca al } \\
\text { bosque primario } \\
\text { Enriquecimiento } \\
\text { en áreas degra- } \\
\text { dadas (para } \\
\text { productores con } \\
\text { más recursos) }\end{array}$ & & $\begin{array}{l}\text { Enriqueci- } \\
\text { miento en } \\
\text { áreas } \\
\text { inadecuadas } \\
\text { para cultivo } \\
\text { intensivo }\end{array}$ & \\
\hline $\begin{array}{l}\text { Bosque (> 8-10 } \\
\text { años) para } \\
\text { producción } \\
\text { comercial } \\
\text { (maderables y } \\
\text { no maderables) }\end{array}$ & & & $\begin{array}{l}\text { Regeneración } \\
\text { natural y e } \\
\text { nriquecimiento } \\
\text { en áreas } \\
\text { pequeñas de } \\
\text { productores } \\
\text { especializados }\end{array}$ & $\begin{array}{l}\text { Regeneración } \\
\text { natural }\end{array}$ & & \\
\hline $\begin{array}{l}\text { Bosque de } \\
\text { conservación } \\
\text { (> } 20 \text { años) }\end{array}$ & & & $\begin{array}{l}\text { Protección de } \\
\text { especies útiles }\end{array}$ & $\begin{array}{l}\text { Protección de } \\
\text { especies útiles }\end{array}$ & $\begin{array}{l}\text { Protección de } \\
\text { especies útiles } \\
\text { (áreas } \\
\text { pequeñas) }\end{array}$ & $\begin{array}{l}\text { Protección de } \\
\text { especies útiles } \\
\text { (áreas } \\
\text { pequeñas) }\end{array}$ \\
\hline
\end{tabular}


Los pequeños propietarios en la etapa pionera temprana son los que más se interesan en la producción de bienes de subsistencia, debido a su pobre acceso a los mercados, a la vez que cuentan con recursos muy limitados de capital y mano de obra e inseguridad en la tenencia de la tierra. De otro lado, estos tienen acceso a extensas áreas de bosques primarios, a partir de los cuales pueden obtener productos de subsistencia. Por tanto, es poco probable que estos agricultores decidan invertir en plantaciones de enriquecimiento, aunque sí podría ser atractivo para ellos dedicar algún esfuerzo a la regeneración natural (mayormente aquella de especies de alto valor que oportunísticamente crece en los barbechos), dados sus bajos requerimientos en recursos. Los sistemas más intensivos de cultivos multi-estrato serían de más interés en la etapa de cierre de frontera o frontera vieja, pero sus requerimientos relativamente altos en recursos, la volatilidad de precios de productos forestales y la falta de conocimiento técnico menor intensidad, tales como la plantación de enriquecimiento, pueden ser más aceptables para estos agricultores; sin embargo, debido a la escasez de tierra, los enriquecimientos estarían restringidos a pequeñas áreas consideradas inapropiadas para la producción intensiva de cultivos.

Barbechos largo (>10 años) para la producción comercial de productos forestales. Un impedimento importante para la producción comercial es el tiempo que toma obtener valor comercial. Cuanto mayor es la degradación del suelo, mayor es el tiempo que toma para la recuperación de la productividad, más bajo será el potencial económico y menores las opciones tecnológicas (Anderson 1990; Finegan 1992). Por consiguiente, la producción comercial de productos maderables y no maderables requiere de una cierta selección de tierra de mejor calidad, o niveles más altos de mano de obra y manejo. Otros impedimentos incluyen las restricciones del gobierno sobre el aprovechamiento de productos forestales y la baja capacidad de los productores para buscar compradores para su productos y cumplir con la calidad y cantidad requerida.

Así, bajo la situación actual, la producción comercial de productos forestales entre agricultores de pequeña escala es probable que se limite a un reducido número de ellos con más recursos en la etapa de mercados emergentes. Sin embargo, a menudo este tipo de productores son relativamente especializados y podrían llegar a generar empleo en las comunidades rurales (Padoch \& Pinedo Vasquez 1996; Brodie et al. 1997). Entre las tecnologías disponibles, la regeneración natural pre-existente, complementada o no con plantaciones de enriquecimiento, serían las más aceptables. La inducción de la regeneración es poco probable, debido a sus altos requerimientos de recursos y a la naturaleza fragmentaria de muchas áreas de bosque secundario en esta etapa.
En la etapa de frontera vieja, la tierra bajo bosque secundario es muy limitada y proclive a ser degradada con altos niveles de infestación de malezas, fuegos frecuentes en áreas vecinas y la falta de fuentes de semillas debido a la escasez y lejanía del bosque primario. Estos factores probablemente estén limitando la adopción a apenas un número muy reducido de productores especializados en pequeñas áreas de bosque secundario que serían inapropiadas para otros propósitos. La adopción de estas tecnologías parece más plausible entre productores de gran escala en la etapa de mercados emergentes. Desde que la especulación de tierras es el motivo principal detrás de la existencia de bosques secundarios, los ganaderos podrían estar interesados en técnicas de regeneración natural a través de las cuales el valor de la tierra puede aumentar con sólo alguna inversión moderada. La distancia de bosques secundarios a los bosques primarios puede reducir la efectividad de la regeneración natural y por tanto impedir su adopción. En áreas de frontera vieja, es posible que la tierra bajo bosque secundario esté más degradada, disminuyendo así el potencial económico que puede esperarse del bosque secundario.

Bosques de conservación (retención por $>20$ años). En algunas areas como Pucallpa, donde la conciencia ambiental y la apreciación de la importancia de preservar los bosques parecen estar difundidas entre los pequeños agricultores (Smith et al. 1997), es probable que en las etapas de mercados emergentes y de frontera vieja los pequeños agricultores lleven a cabo prácticas simples de conservación que requieren un mínimo de capital o de mano de obra, tales como la protección de especies útiles en áreas de bosque secundario. En la etapa de frontera vieja, estas áreas serían mínimas. Sin embargo, no sabemos si estos resultados se pueden generalizar. Tales medidas pueden ser implementadas también por agricultores o ganaderos de gran escala en los que se ha desarrollado una conciencia ambiental, aunque aún se conoce muy poco si estas actitudes están difundidas o no. Otras medidas, tales como la protección contra el fuego, o algún tipo de manejo extensivo de la fauna, serían poco factibles que se den, dada la dificultad de capturar retornos económico a los recursos requeridos para tales actividades.

\section{Productores indígenas}

Barbecho mejorado (con edades $<5$ años). De los tipos de agricultores indígenas, sólo los semi-sedentarios y los que están en contacto con mercados podrían estar interesados en barbechos mejorados. El costo de oportunidad de la tierra es bajo en la fase semi-sedentaria, ya que aún se tiene acceso a tierras no ocupadas. Estos agricultores estarían más interesados en tecnologías de cobertura de leguminosas. Cuando se llega a la fase de contacto con el mercado, el costo de oportunidad de la tierra aumenta, ya que esta se vuelve un recurso esca- 
so. Entre estos agricultores, el "mulching" y los abonos orgánicos serían las opciones de mayor interés.

\section{Barbechos mejorados para diversificacion de ingresos.} Los barbechos mejorados son una opción apropiada para generar ingresos, más que todo entre productores en contacto con mercados. Ello se daría mayormente por medio de sembrios de especies de interés especial y menos a través de un manejo de la vegetación natural. La tecnología de un manejo de este tipo es relativamente facil de implementar, pero requiere que se obtengan productos que pueden ser vendidos en el mercado. Por ello, esta opción parece menos apropiada para agricultores semi-sedentarios, que tienen menos acceso al mercado. Para ambos tipos de agricultores, no sería muy factible intensificar el manejo para mejorar la producción destinada al consumo casero más alla de lo que ya hacen, debido a que los productores semisedentarios tienen acceso al bosque para productos que necesitan, mientras que aquellos en contacto con el mercado estarán mas interesados en producir para la venta y menos para el autoconsumo.

Barbecho de largo tiempo. El manejo de barbechos por largo tiempo tendrá sentido para agricultores en contacto con mercados en el caso de productos especiales, tales como frutas, desarrollándose lo que podrían ser huertos frutales o la arboricultura. También podría ser de interés la producción de madera redonda cuando se tiene un mercado con buenos precios. Los agricultores semi-sedentarios podrán estar interesados en manejar barbechos por más tiempo cuando puedan producir en base a especies que permitan un valor agre- gado. La madera que pueda ser aserrada en el lugar de producción sería una opción para ellos, así como para los productores en contacto con el mercado.

Bosque de conservación. Esta opción tendrá más sentido para agricultores en contacto con el mercado, que tienen tenencia de tierra suficientemente segura y otras opciones para obtener ingresos. Se podría combinar bien con la producción de madera aserrada.

En el Cuadro 9 (siguiente página) se resumen las apreciaciones anteriores para este grupo de productores.

Los resultados en los cuadros 8 y 9, tanto para productores colonos e indígenas, revelan que los tipos de tecnologías que son más probables de ser adoptados por diferentes tipos de productores en las distintas etapas de intensificación, varían ampliamente. Por consiguiente, una cuidadosa selección de las tecnologías en función de sus requerimientos para los productores tendría un potencial considerable para mejorar la eficiencia del desarrollo de tecnologías, así como de sus posibilidades de adopción. Cabe enfatizar una vez más que las funciones para un mismo bosque pueden cambiar a través del tiempo, según cambios en la etapa de intensificación de sus propietarios.Asi que este marco conceptual dinamico indica que la estrategia para manejar un bosque secundario puede ser una combinacion de opciones tecnologicas atraves del tiempo. Esto indica la importancia de usar un marco conceptual dinamico y integrar las funciones del bosques secundarios relacionada a la agricultura (como recuperacion de fertilidad de suelos) con funciones relacionada a la produccion forestal.

Cuadro 9. Opciones tecnológicas para agricultores indígenas según la fase de intensificación

\begin{tabular}{|l|l|l|l|}
\hline \multicolumn{1}{|c|}{ Opciones tecnológicas } & Migratoria & \multicolumn{1}{|c|}{ Semi-sedentario } & Con acceso al mercado \\
\hline $\begin{array}{l}\text { Barbecho de corta edad para } \\
\text { mejorar el suelo (1-5 años) }\end{array}$ & & $\begin{array}{l}\text { Cubertura de leguminosas, } \\
\text { "mulching" e incorporación de } \\
\text { abonos orgánicos }\end{array}$ \\
\hline $\begin{array}{l}\text { Barbecho de edad media } \\
\text { (5-10 años) }\end{array}$ & $\begin{array}{l}\text { Intensificación del manejo de } \\
\text { productos del barbecho } \\
\text { tradicionalmente ya manejado } \\
\text { y cosechado para su venta en } \\
\text { el mercado }\end{array}$ & $\begin{array}{l}\text { Enriquecimiento con especies } \\
\text { que tienen valor en el mercado }\end{array}$ \\
\hline $\begin{array}{l}\text { Barbecho de edad avanzada } \\
\text { (> 10 años) }\end{array}$ & $\begin{array}{l}\text { Producción de madera aserrable } \\
\text { o especies que permiten un } \\
\text { valor agregado }\end{array}$ & $\begin{array}{l}\text { Arboricultura o madera } \\
\text { redonda cuando tiene buen } \\
\text { precio }\end{array}$ \\
\hline $\begin{array}{l}\text { Bosque de conservación } \\
\text { (> 20 años }\end{array}$ & $\begin{array}{l}\text { En conjunto con producción } \\
\text { de madera aserrable }\end{array}$ \\
\hline
\end{tabular}


Si bien los resultados de este ejercicio deberían tomarse apenas como indicativos, dada la falta de datos empírico, no obstante, estos parecen implicar que ninguna de las opciones tecnológicas mencionadas serían (suficientemente) apropiadas para los grandes ganaderos en las primeras dos etapas de intensificación y en la categoría de casos "accidentales". Estas serían precisamente las categorías donde es posible encontrar las mayores áreas de bosque secundario.

Los resultados también indican que los productores indígenas pueden ser más receptivos que los productores colonos a un manejo más intensivo de los bosques secundarios, dada la importancia de este recurso en su sistema tradicional de uso de la tierra. Sin embargo, el peor acceso al mercado puede implicar que sólo los productores de mayor capacidad gerencial llegarían a adoptar un manejo intensivo del bosque secundario.

De otro lado, los resultados de este ejercicio también parecen implicar que, bajo las actuales condiciones, es improbable que ciertas tecnologías sean apropiadas para cualquiera de las categorías de productores que se han identificado, es decir, parece que algunas tecnologías que requieren de muchos recursos tienen muy poca probabilidad de ser adoptadas por cualquier clase de productor (compárense los cuadros 7 y 8 ).

No obstante, esta situación podría cambiar si ocurren intervenciones de política. En la sección 7 investigamos las condiciones bajo las cuales estas podrían requerirse.

\section{INTERVENCIONES DE POLITICA}

En esta sección investigamos las circunstancias bajo las cuales las intervenciones de política pueden fomentar la contribución que los bosques secundarios son capaces de hacer a la conservación ambiental y el alivio de la pobreza. Los bosques secundarios pueden contribuir a la protección ambiental de dos maneras: primero, tumbar y cultivar el bosque secundario en lugar de bosque primario puede reducir la presión sobre este último y, segundo, el mantenimiento de la cobertura del bosque secundario puede mitigar algunos de los impactos ambientales adversos de la destrucción de los bosques primarios. Además, el uso productivo de los bosques secundarios por pequeños propietarios puede contribuir a aliviar la pobreza. En este documento enfocaremos sólo las políticas más próximamente relacionadas a estos roles de los bosques secundarios.

\section{Políticas que pueden aumentar la rentabilidad de los bosques secundarios}

Estas politicas pueden ser de cuatro clases principales: 1) políticas relacionadas a mercados para productos del bosque secundario; 2) políticas relacionadas al marco legislativo; 3) políticas para permitir a los productores la captura de los beneficios de mantener los bosques secundarios y 4) políticas para aumentar la investigación. Trataremos de ofrecer a continuación algunos ejemplos para cada una de estas clases.

En el area del mercadeo, un gran impedimento es la falta de capacidad gerencial. Los productores carecen de información sobre la demanda de mercado y las características deseadas de calidad y cantidades deseadas y de quiénes son los compradores potenciales. La política puede ayudar aquí suministrando esta información a través de un apoyo al establecimiento de organizaciones no gubernamentales (ONGs) que cumplan tal tarea. Asimismo, se pueden mencionar políticas para el desarrollo de mercados para productos forestales no maderables, incentivos para industrias de procesamiento y para alianzas estratégicas entre agroindustrias y organizaciones de productores (Cámara Nacional Forestal 1996).

En relación con las leyes ambientales, se puede mencionar la reforma del marco legislativo que regula el aprovechamiento de productos forestales. En muchos casos, estas regulaciones aumentan los costos de transacción del aprovechamiento de productos forestales sin conseguir la conservación, mayormente porque son difíciles de hacer cumplir. Por ejemplo, es necesario tener una licencia para vender madera. La idea es controlar y a la vez lograr que se adopten prácticas de manejo sostenible. Muchas veces es un impedimento para los pequeños productores, pero la extracción ilegal continúa.

También se hace necesario desarrollar un marco legislativo para los derechos de propiedad intelectual. Muchas veces, los productos forestales no maderables tienen mercado por una época muy corta, hasta que se desarrollan productos sintéticos que son capaces de reemplazarlos. En este caso, no hay mecanismos para pagar los derechos de "royalty".

Con referencia a políticas que puedan favorecer la captura de beneficios de los servicios ambientales de los bosques, han empezado a surgir recientemente algunos mecanismos que pueden fomentar el mantenimiento de bosques secundarios y su manejo productivo en forma sostenible. Entre estos se tiene el desarrollo de nichos de mercado para maderas tropicales certificadas provenientes de bosques bajo manejo sostenible. Otro desarrollo reciente es el surgimiento de mecanismos que compensan a los usuarios de la tierra que proveen servicios ambientales, tales como la protección de cuencas o el secuestro de carbono. Un ejemplo es el comercio internacional en servicios asociados al secuestro de carbono, en el cual a las compañías de energía en países desarrollados se les permite que cumplan las metas de reducción de emisiones de carbono en sus países de orígen a través de arreglos de transferencia de pago a agricultores en países en desarrollo que preserven o planten bosques (Pearce 1996; Swisher y Masters 1992). Smith et al. (1997) muestran 
que este tipo de "comercio" puede ser rentable para productores pequeños en Pucallpa y, al mismo tiempo, para compañías de energía. Estos mecanismos pueden estimular la adopción de tecnologías para la producción comercial de productos forestales o para aumentar el área en bosque secundario.

Otros aspectos que pueden jugar un rol incluyen una mayor seguridad de la tierra y la abolición de otros desincentivos para el manejo sostenible, tales como la volatilidad en los precios y la demanda para productos forestales.

Sin embargo, cada una de estas políticas requiere de un cuidadoso examen para comparar su probable efectividad con sus costos directos, así como su impacto en términos de equidad, de su efecto sobre otros sectores de la economía y de su viabilidad polítia.

Respecto a la última clase de intervenciones de política, para apoyar la investigación hacia el desarrollo de tecnologías apropiadas y estudios sobre las políticas necesarias, identificamos en la última sección algunos de los vacíos de envestigación sobre los bosques secundarios.

\section{Correspondencia entre políticas y etapas de intensificación}

Para este analisis, usaremos el marco desarrollado por Tomich et al. (1996). En el caso de los bosques secundarios, las intervenciones de política son indicadas cuando el talar un bosque secundario es más rentable que mantener un bosque secundario por razones de distorsiones de política (tales como incentivos para la especulación de tierras, subsidios para la producción agrícola) o por externalidades, esto es, beneficios que no pueden ser capturados por individuos que toman decisiones sobre el uso de la tierra (como los servicios ambientales: beneficios de la conservación de la biodiversidad o el secuestro de carbono).

Hoy en día apenas se están desarrollando mecanismos para compensar a los productores por los servicios ambientales de los bosques secundarios (como el comercio basado en el secuestro de carbono atmosférico). Se puede decir que la cantidad y la duración del bosque secundario que se conserva siempre sería menor de lo que sería óptimo para la sociedad. Por lo tanto, intervenciones de política que permitan a los productores obtener alguna compensación por los servicios ambientales que prestan los bosques secundarios serían indicadas para las tres etapas de intensificaion. Además, en algunos casos hay distorsiones econámicas que favorecen la tala del bosque secundario.

Siguiendo el marco conceptual de Tomich et al. (1996), hay tres casos que son relevantes para los bosques secundarios:

- $\quad$ se requiere de intervenciones si mantener el bosque secundario es socialmente deseable, pero no privadamente rentable (caso 1);
- alternativamente, se requieren intervenciones cuando se implementan actividades socialmente indeseables (como talar los bosques secundarios), porque eso es rentable a nivel privado (caso 2 );

- si el mantenimiento del bosque secundario es rentable tanto socialmente como privadamente caso 3), no se requiere de intervenciones.

Usando este marco conceptual, analizamos las necesidades de intervención para cada etapa del proceso de intensificación.

\section{Productores colonos}

Etapa pionera temprana. En esta etapa parece que el área de bosques secundarios está aumentando en fincas de pequeña escala (Cuadro 3). En comparación, las áreas de cultivo tienden a ser relativamente pequeñas. Por tanto, la formación de bosques secundarios aparentemente es consistente con los objetivos de los agricultores (esto es, privadamente rentable). También socialmente deseable, ya que estos bosques secundarios están contribuyendo a la protección ambiental y en particular están recuperando la calidad del suelo. Mientras que los bosques secundarios también pueden usarse para generar ingreso, la no adopción de tecnologías para hacerlo parece estar relacionada más a la disponibilidad de bosque primario, antes que a las distorsiones de política. La no adopción de tecnologías para acortar el periodo de barbecho (y reducir así la presión sobre el bosque primario), también parece estar relacionada principalmente con la abundancia de tierra, antes que con distorsiones de política. Claro que, como indicamos antes, el desarrollo de mecanismos para compensar por algunos servicios ambientales podrían resultar en un aumento del área bajo bosque secundario, pero la implementación de cualquier mecanismo sería sumamente dificil en esta etapa debido a la mala accessibilidad y el muy poco cumplimiento de la ley. Así, la situación en esta etapa correspondería al caso 3 para los pequeños propietarios, o sea, no parecen ser necesarias intervenciones estrechamente relacionadas con el rol de los bosques secundarios. (Esto, por supuesto, no quiere decir que no se requiera de políticas para reducir la destrucción de los bosques primarios).

Para los grandes ganaderos, los bosques secundarios tienden a ocupar áreas sustantiales y, por tanto, son privadamente rentables. Si bien es socialmente rentable desde el punto de vista ambiental, es socialmente indeseable desde el punto de vista de eficiencia, dado que esta forma de uso de la tierra está principalmente motivada por distorsiones de política que fomentan la especulación de tierras. La remoción de algunos de los incentivos para la especulación de tierras, tales como la inestabilidad macroeconómica y el crédito subsidiado, está ahora en camino en muchos 
países, notoriamente en Brasil. Otros incentivos, tales como la construcción de caminos de penetración, parece que todavía continúan. Es dificil predecir qué pasaria si estas distorsiones son removidas. Es probable que dichas tierras sean abandonadas y se queden como bosque secundario. De esta manera, las intervenciones tampoco serían necesarias en esta etapa para los grandes ganaderos.

Etapa de mercados emergentes. En las parcelas de los pequeños productores, mientras que el área en bosque secundario aumenta en relación a la etapa del frente pionero, el área de bosque primario se reduce fuertemente, conduciendo a una reducción general en la cobertura forestal (Figura 1). Así, sería socialmente deseable tener más tierra en bosque secundario, que lo que es privadamente rentable. Esto es en parte porque las distorsiones de política pueden estar reduciendo los retornos de bosques secundarios en relación a los cultivos anuales y las pasturas, y en parte porque los agricultores son incapaces de capturar los beneficios que proporciona los servicios ambientales al mantener bosques secundarios. En esta situación, las intervenciones podrían aumentar la rentabilidad de dejar en barbecho e inducir a mayores áreas en barbecho de ciclo largo.

El Cuadro 8 muestra que, sin intervenciones, principalmente las tecnologías orientadas a la susbsistencia son las que más probablemente sean adoptadas. Estas, a su vez, no tendrían mayor impacto en el cambio de uso de la tierra. Tecnologías tales como la producción comercial de productos forestales y los sistemas agroforestales multiestrato - que tienen el potencial de aumentar sustancialmente los ingresos y por consiguiente inducir al cambio en el uso de la tierra - parecen en cambio tener una baja probabilidad de adopción, excepto en áreas muy limitadas. De ahí que las políticas que aumentan la rentabilidad al mantener bosques, así como las políticas relacionadas con el mercadeo parecen particularmente indicadas en esta etapa. Mecanismos que permitan a los productores capturar los beneficios ambientales de mantener bosques secundarios también serían indicadas, así como reformas en el marco legislativo y el apoyo a la investigación.

En las grandes fincas ganaderas, donde los bosques secundarios existen principalmente debido a la especulación, la remoción de distorsiones de política que fomentan la especulación es probable que conduzca a la reconversión de bosques secundarios a pasturas. Sin embargo, estos productores tienen los recursos requeridos para la producción comercial en base a bosques secundarios, pero es poco probable que los utilicen sin políticas que incrementen la rentabilidad del manejo de bosques secundarios. Nuevamente, parece que aquí se requieren todas las intervenciones mencionadas para los pequeños productores. Sin embargo, cabe notar que estas intervenciones puede aumentar los ingresos de grandes productores y a su vez aumentar la inequidad en la distribución de ingresos.

Etapa de frontera vieja. El área en bosque secundario es mínima, tanto para pequeños como grandes productores, mientras que los cultivos ocupan áreas extensas. Aquí los beneficios sociales de mantener el bosque parecen ser sustancialmente mayores que los privados. De esta manera, las intervenciones de política tendrán que hacer una diferencia importante en la rentabilidad de mantener bosques secundarios antes de que sean efectivas. Antes que pensar en intervenciones de política en esta fase, sería más efectivo dirigir estas a la etapa de mercados emergentes. Si las políticas son exitosas en aumentar el área bajo bosque secundario en la etapa de mercados emergentes, esto bien podría prevenir, hasta cierto punto, que los bosques secundarios se talen cuando los productores pasen a la etapa de frontera vieja. Esto indica la utilidad de usar un marco conceptual dinámico.

\section{Productores indígenas}

Agricultura migratoria. Este caso es similar al de la etapa pionera temprana de los colonos, en el sentido que el bosque secundario es rentable desde el punto de vista social y privado. Por ello, la necesidad de intervención sería muy baja. Además, las peores condiciones de accesibilidad y la naturaleza migratoria de estas poblaciones implican que cualquier intervención sería sumamente difícil.

Semi-sedentarismo. Aunque aquí el bosque secundario es privadamente rentable, los pocos productos que son extraídos o producidos en el bosque secundario para fines de comercialización ofrecen oportunidades para mejorar los ingresos. Intensificar el manejo del bosque secundario entre estos productores también puede mejorar el cuadro de productos de consumo y así mejorar en general el bienestar de estas poblaciones. Las políticas sobre el mercadeo pueden tener relevancia especial para algunos productos forestales no maderables que son de alto valor y fáciles de transportar. En esta etapa las reformas en el marco legislativo (especialmente los derechos de propiedad intelectual) son igualmente deseables..

Con acceso al mercado. En este caso hay una oportunidad de aprovechar el conocimiento tradicional que estas poblaciones disponen sobre el bosque secundario, a fin de aumentar su uso comercial. Las políticas sobre el mercadeo son sumamente importantes aquí, especialmente las que fomenten a las ONGs para ayudar a estas poblaciones con informaciones sobre mercados. Además, son indicadas políticas que apoyen la investigación, mecanismos para capturar los beneficios asociados con los servicios ambientales y reformas en el marco legislativo. Lo anterior puede resultar en un 
aumento significativo en el área y edad de bosques secundarios y, a la vez, aumentar el bienestar de las poblaciones pobres.

\section{VACIOS EN LA INVESTIGACION}

Los planteamientos y resultados anteriores nos llevan a señalar algunos de los vacíos que se detectan actualmente en la investigación sobre los bosques secundarios con fines de manejo. Entre estos, caben destacar entre estos:

- Dónde se encuentran las extensiones grandes de bosques secundarios, en qué etapa de intensificación y con qué tipo de productor.

- Qué prácticas de manejo convienen más en las distintas etapas de intensificación.

- Cómo relacionar mejor los aspectos biofísicos con las etapas de intensificación.

- Entre los aspectos biofísicos, se puede agregar: Cómo reducir los requerimientos de capital y mano de obra para productos que se pueden comercializar. Qué productos pueden mejorar el bienestar de las poblaciones pobres (por ejemplo, en los aspectos nutricionales). Cuál sería el impacto ecológico de estrategias de comercialización.

- Qué intervenciones de política podrían ser más efectivas en las distintas etapas y cuáles serían sus costos directos y sobre otros sectores de la economía.

- Verificar las hipótesis sobre la correspondencia entre las tecnologías y políticas y las etapas de intensificación, a fin de mejorar el enfoque de intervenciones.

\section{CONCLUSIONES}

En este documento hemos intentado contribuir a una estrategia para la investigación en bosques secundarios. Introducimos un marco conceptual para relacionar los aspectos biofísicos de las tecnologías con las características socioeconómicas de los productores. Pensamos que esto debiera ayudar a enfocar el desarrollo de tecnologías en opciones que más probablemente puedan tener un impacto.

Creemos que es importante el empleo de un marco dinámico, basado en cambios en el tiempo en el grado de intensificación, ya que permite enfocar la investigación en escenarios futuros, proporcionando así oportunidades para prevenir, antes que corregir, la degradación de recursos antes que esta ocurra. Este marco conceptual, además, permite el análisis de los bosques secundarios como parte integral del sistema total del uso de la tierra.

Finalmente, deseamos enfatizar una vez más que los resultados de este ejercicio son meramente indicativos y que se requiere de más datos empíricos. 


\section{REFERENCIAS DE LA LITERATURA}

Alcorn, J. 1990. Indigenous agroforestry strategies meeting farmers' needs. In: A.B. Anderson (ed.), Alternatives to Deforestation: Steps Toward Sustainable Use of the Amazon Rain Forest, pp. 141-151. Columbia University Press, New York.

Almeida, A.L.O. de and J.S. Campari. 1995. Sustainable Settlement in the Brazilian Amazon. World Bank, Washington, DC and Oxford University Press. Oxford.

Almeida, O.T. de and C. Uhl. 1995. Developing a quantitative framework for sustainable resource-use planning in the Brazilian Amazon. World Development 23: 1745-64.

Anderson, A.B. (ed.). 1990. Alternatives to Deforestation. Steps Toward Sustainable Use of the Amazon Rain Forest. Columbia University Press, New York.

Bakker, L.M. 1993. Colonization and Land Use In The Humid Tropics of Latin America. Ministry of Foreign Affairs, Directorate General of International Cooperation, The Hague/National Reference Centre for Nature Management of the Ministry of Agriculture, Nature Management and Fisheries/BOS Foundation, Organization for International Forestry Cooperation, the Netherlands. Werkdocument IKC-N/LNV no. 34.

Balée, W. and A. Gely. 1989. Managed forest succession in Amazonia: The Ka'apor case. Advances in Economic Botany 7: 129-158.

Boserup, E. 1965. The Conditions of Agricultural Growth. Aldine Publishing Company, Chicago.

Brodie A.W., R. Labarta Chavarri and J.C. Weber. 1997. Tree Germplasm Management and Use On-farm in the Peruvian Amazon: A Case Study from the Ucayali Region, Peru. ODI, London and ICRAF, Kenya.

Brown, S. and A. Lugo. 1990. Tropical secondary forests. Journal of Tropical Ecology 6: 1-32.

Budowski, G. 1961. Studies on Forest Succession in Costa Rica and Panama, Ph.D. Thesis Yale University, New Haven. Conn.

Budowski, G. 1965. Distribution of tropical American rain forest species in the light of successional process. Turrialba 15: 40-42.

Cabrera, C. 1992. Informe de consultoría, diagnóstico forestal nacional de Guatemala. International Union for Nature Conservation (IUCN) and Intercooperation, Guatemala.

Cámara Nacional Forestal. 1996. Proyecto modelo demostrativo de manejo de bosques secundarios en la Amazonía Peruana con fines de producción comercial. Camara Nacional Forestal, Lima, Perú.

Chibnik, M. 1991. Quasi-ethnic groups in Amazonia. Ethnology 30: 167-182.

Current, D., E. Lutz and S. Scherr. (eds). 1995. Costs, Benefits and Farmer Adoption of Agroforestry. Project Experience in Central America and the Caribbean. World Bank Environment Paper Number 14, World Bank, Washington, DC.

de Jong, W. 1995. Diversity, Variation, and Change in Ribereño Agriculture and Agroforestry. PhD Dissertation, Agricultural University Wageningen, the Netherlands.

Denevan, W.M. and C. Padoch. 1988. Introduction: The Bora agroforestry project. In: W.M. Denevan and C. Padoch (eds), Swidden-fallow Agroforestry in the Peruvian Amazon. Advances in Economic Botany 5: 1-7.

Denich, M. 1989. Untersuchungen zur Bedeutung junger Sekundärvegetation für die Nutzungssystemproduktivität im östlichen Amazonasgebiet, Brasilien. Göttinger Beiträge zur Land- und Forstwirtshaft in den Tropen und Subtropen, Heft 46. 265 S. + Anhang, Göttingen.

Dourojeanni, R.M. 1987. Aprovechamiento del barbecho forestal en áreas de agricultura migratoria en la Amazonía peruana. Revista Forestal del Perú 14(2): 15-61.

Dourojeanni, R.M. 1990. Amazonía ¿Qué hacer? Centro de Estudios Teológicos de la Amazonía, Iquitos, Perú.

Dubois, J.C.L. 1990. Los barbechos forestales como forma útil del uso de la tierra en fronteras agrícolas de la Amazonia. In: Anderson, A.B. (ed.), Alternativas a la deforestación, pp. 285-302. (Trad. orig. inglés: Alternatives to Deforestation: Steps Toward Sustainable Use of the Aamazon Rain Forest). Fundación NaturaAbya Yala-Museo Emilio Goeldi. Cayambe, Ecuador. 
Ewel, J. 1980. Tropical succession: manifold routes to maturity. Biotropica 12 (Suppl. Trop. Succession): 2-7.

Ewel, J. 1981. Secondary forests: The tropical wood resource of the future. In: Simposio internacional sobre las Ciencias Forestales y su contribución al desarrollo de la América tropical, San José, 11-17 de octubre de 1979, pp. 53-60. EUNED, San José, Costa Rica.

FAO. 1995. Forest Resources Assessment 1990. FAO Forestry Paper 112. Rome, Italy.

FAO. 1996. Forest Resources Assessment 1990. Survey of Tropical Forest Cover and Study of Change Processes. FAO Forestry Paper 130. Rome, Italy.

Faber-Langendôen, D. 1992. Ecological constraints on rain forest management at Bajo Calima, Western Colombia. Forest Ecology and Management 53: 213-244.

Fallas, J. and C. Morera. 1993. Cambios en cobertura y evaluación del uso de la tierra en la I etapa del proyecto de riego Arenal - Tempisque para los años 1986 y 1992. Universidad Nacional, Costa Rica.

Fearnside, P. 1996. Amazonian deforestation and global warming: carbon stocks in vegetation replacing Brazil's Amazon forest. Forest Ecology and Management 80: 21-34.

Fearnside, P. and W.M. Guimarâes. 1996. Carbon uptake by secondary forests in Brazilian Amazonia. Forest Ecology and Management 80: 35-46.

Finegan, B. 1992. El potencial de manejo de los bosques húmedos secundarios neotropicales de las tierras bajas. CATIE, Turrialba, Costa Rica

Finegan, B. 1996. Pattern and process in neotropical secondary rain forests: The first 100 years of succession. Tree 11(3): 119-124.

Finegan, B. y C. Sabogal. 1988. El desarrollo de sistemas de producción sostenible en bosques tropicales húmedos de bajura: un estudio de caso en Costa Rica. El Chasqui (CATIE) 17: 3-24 y 18: 16-24.

Fontaine, R.G., A. Gómez-Pompa and B. Ludlow. 1978. Secondary successions. In: UNESCO/UNEP/FAO, Tropical Forest Ecosystems: A State-of-the-Knowledge, pp. 216-232. UNESCO, Paris.

Gómez-Pompa, A. 1991. Learning from traditional ecological knowledge: insights from mayan silviculture. In: Gómex-Pompa, A., T.C. Whitmore and M. Hadley (eds), Rain Forest Regeneration and Management. Volume 6. UNESCO, Paris and The Parthenon Publishing Group, Carnforth, UK.

Gómez-Pompa, A. and C. Vázquez Yanes. 1974. Studies on the secondary succession of tropical lowlands: The life cycle of secondary species. In: Proceedings of the First International Congress of Ecology. The Hague, the Netherlands. Sept. 8-14, 1974, pp. 336-342. Centre for Agriculture Publishing and Documentation, Wageningen, the Netherlands.

Gómez-Pompa, A., C. Vasquez-Yanes, S. del Amo and A. Butanda. (eds). 1979. Investigaciones sobre la regeneración de selvas altas en Veracruz, México. Comp. Edit. Continental, S.A. Mexico. 676 pp.

Gräfe, W. 1981. Struktur- und Dynamikuntersuchungen in jungen Zweitwuchsbeständen der westlichen Llanos Venezuelas. Dissertation Universität Göttingen (Germany).

Guariguata, M.R., R.L. Chazdon, J.S. Denslow, J.M. Dupuy and L. Anderson. En prensa. Structure and floristics of secondary and old-growth forest stands in lowland Costa Rica. Vegetatio.

Guevara, S., S.E. Purata and E. van der Maarel. 1986. The role of remnant forest trees in tropical secondary succession. Vegetatio 66: 77-84.

Guillén, A.L. 1993. Inventario comercial y análisis silvicultural de bosques húmedos secundarios en la región Huétar Norte de Costa Rica. Tesis, Instituto Tecnológico de Costa Rica, Cartago, Costa Rica. 74 pp. + annexes.

Holt, E. n.d. Stabilizing the agricultural frontier in Central America, observing Guamiles: tradition and potential. Draft.

Homma, A.K.O., R.T. Walker, F.N. Scatena, A.J.de Conto, R. de A. Carvalho, A.C.P. Neves da Rocha, C.A.P. Ferreira and A.I. Moreira dos Santos. 1993. La dinámica de deforestaçâo y quemadas en el Amazonas: un análisis microeconómico. CPATU-EMBRAPA, Belém.

Huising, J. 1993. Land Use Zones and Land Use Patterns in the Atlantic Zone of Costa Rica. Masters Thesis, Agricultural University Wageningen, the Netherlands. 
INTECFOR (Instituto Técnico Forestal). 1993. Manual Técnico Forestal. Managua, Nicaragua.

Irvine, D. 1987. Resource management by the Runa Indians of the Ecuadorian Amazon. Dissertation, Department of Anthropology, Stanford University.

Irvine, D. 1989. Succession management and resource distribution in an Amazonian rainforest. In: D.A.Posey and W. Balée (eds.), Resource Management in Amazonia: Indigenous and Folk Strategies. Advances in Economic Botany 7: 223-238.

Jones, D.W. and R.V. O'Neill. 1993. Human-environmental influences and interactions in shifting agriculture. In: T.R. Lakshmanan and P. Nijkamp (eds), Structure and Change in the Space Economy, 297-309. SpringerVerlag, Berlin.

Kaimowitz, D. 1995. Land tenure, land markets, and natural resource management by large landowners in the Péten and the Northern Transversal of Guatemala. Paper Prepared for delivery at the 1995 meeting of the Latin American Studies Association, The Sheraton Washington, September 28-30.

Kahn, F. 1982. La reconstitucion de la foret tropicale humide, Sud-Ouest de la Cote d'Ivoire. ORSTOM, Collection Memoires No 97, Paris.

Lamprecht, H. 1990. Silvicultura en los trópicos: los ecosistemas forestales en los bosques tropicales y sus especies arbóreas - posibilidades y métodos pare un aprovechamiento sostenido. GTZ, Eschborn, Alemania.

Loker, W.M. 1993. The human ecology of cattle raising in the Peruvian Amazon: The view from the farm. Human Organization 52: 14-24.

Lugo, A.E. and S. Brown. 1982. Tropical forests as sinks of atmospheric carbon. Forest Ecology and Management 54: $239-255$.

Mattos, M.M. and C. Uhl. 1994. Economic and ecological perspective on ranching in the eastern Amazon. World Development 22: 145-158.

Moran, E.F., E.S. Brondizio and E. Mausel. 1994. Secondary succession. National Geographic Research and Exploration 10: 458-476.

Moran, E.F., E. Brondizio, P. Mausel and Y. Wu. 1992. Deforestation in Amazonia and land use change: socioecological data and landsat image analysis. Paper presented at Ecolgocial Society of America Annual Meeting, Symposium on Global Impact of Land Use Change: Linkages Between the Social and Natural Sciences. Honolulu, Hawaii, August 11.

Moran, E.F., A. Packer, E. Brondizio and J. Tucker. 1996. Restoration of vegetation cover in the eastern Amazon. Ecological Economics 18: 41-54.

National Research Council. 1993. Sustainable Agriculture and the Environment in the Humid Tropics. Committee on Sustainable Agriculture and the Environment in the Humid Tropics, National Research Council. Washington, DC. National Academy Press.

Nepstad, D., C. Uhl and E.A. Serrâo. 1990. Surmounting barriers to forest regeneration in abandoned, highly degraded pastures (Paragominas, Para). In: A.B. Anderson, (ed). Alternatives to Deforestation: Steps Toward Sustainable Utilization of Amazon Forests, pp. 215-229. Columbia University Press, New York.

Nepstad, D., C. Uhl and E.A. Serrâo. 1991. Recuperation of a degraded Amazonian landscape: forest recovery and agricultural restoration. Ambio 20: 248-255.

Nerlove, M. and E. Sadka. 1991. Von Thunen's model of the dual economy. Zeitschrift fur Nationalökonomie 54: 97-123.

Nuñez Olivas, O. 1993. Deforestación en Costa Rica: la pesadilla y la esperanza. Esta Semana. (April 13-19): 11-12.

Ortiz, R. 1995. El abandono de pastizales y el surgimiento del bosque secundario. Doc. borrador.

Padoch, C. 1987. The economic importance and marketing of forest and fallow products in the Iquitos region. In: W.M. Denevan and C. Padoch (eds), Swidden-fallow Agroforestry in the Peruvian Amazon. Advances in Economic Botany 5: 74-89.

Padoch, C. and M. Pinedo Vasquez. 1996. Smallholder forest management: Looking beyond non-timber forest products. In: M. Ruiz Pérez and J.E.M. Arnold (eds), Current Issues in Non-timber Forest Products Research, pp. 103-118. CIFOR, Bogor, Indonesia. 
Padoch, C. and W. de Jong. 1989. Production and profit in agroforestry: an example from the Peruvian Amazon. In: J.O.Browder (ed.), Fragile Lands of Latin America, pp. 102-113. Westview Press, Boulder, Co.

Padoch, C., J. Chota Inuma, W. de Jong and J. Unruh. 1985. Amazonian agroforestry: A market-oriented system in Peru. Agroforestry Systems 3: 47-58.

Pearce, D. 1996. Global environmental value and the tropical forests: demonstration and capture, In: W. Adamowicz, P. Boxall, M. Luckert, W. Phillips and W. White (eds), Forestry, Economics and the Environment, pp. 11-48. CAB International, Wallingford, UK.

Posey, D. 1983. Indigenous ecological knowledge and development of the Amazon. In: E. Moran (ed.), The Dilemma of Amazonian Development, pp. 225-257. Westview Press, Boulder, Co.

Richards, M. 1996. A Review of the Options for Colonist Technology Development on the Amazon Frontier. ODI, London.

Saldarriaga, J.G. 1987. Recovery following shifting cultivation. A century of succession in the upper Rio Negro. In: C.F. Jordan (ed.), Amazonian Rain Forests. Ecosystem Disturbance and Recovery, pp. 24-33. Ecological Studies. Vol. 60. Springer Verlag. New York.

Saldarriaga, J.G., D.C. West, M.L. Tharp and C. Uhl. 1988. Long-term chronosequence of forest succession in the upper Rio Negro of Colombia and Venezuela. Journal of Ecology 76: 938-958.

Scatena, F.N., R.T. Walker, A. Homma, A. de Conto, C. Palheta, R. de Amorim, A. Neves da Rocha, A. Moreira and P. Mourato. 1996. Cropping and fallow sequences of small farms in the 'terra firme' landscape of the Brazilian Amazon: a case study from Santarem, Para. Ecological Economics 18: 29-40.

Schneider, R.R. 1995. Government and the Economy on the Amazon Frontier. World Bank Environment Paper 11. The World Bank, Washington, DC.

Scott, G.A.J. 1987. Shifting cultivation where land is limited. Campa Indian agriculture in the Gran Pajonal of Peru. In: C.F. Jordan, (ed.), Amazonian Rain Forests. Ecosystem Disturbance and Recovery, pp. 34-45. Ecological Studies. Vol. 60, Springer Verlag. New York.

Secretaría de Planificación, Coordinación y Presupuesto (SECPLAN)/Secretaría de Recursos Naturales (SRN). 1994. IV Censo Nacional Agropecuario. Tegucigalpa.

Serrâo, E.A. 1994. Technologies and policies for containing deforestation in tropical moist forests: the case of the Amazon. Expanded version of the paper presented at the "Regional Seminar on Research Needs and Priorities on Forestry and Agroforestry Policies, San Jose, Costa Rica, July 1993. A contribution to the Dialogue on Science, Forests and Sustainability, Indonesia, December, 1994.

SHIFT Project. 1993. Studies on Human Impact on Forests and Floodplains in the Tropics. Summaries of of lectures and posters presented at the I SHIFT Workshop, Belem, March 8-13 1993.

SHIFT Project. 1995. Studies on Human Impact on Forests and Floodplains in the Tropics. Summaries of lectures and posters presented at the II SHIFT Workshop, Cuiaba, July 10-14 1995. Univ. Fed. Mato Grosso.

Sips, P.A. 1993. Management of Tropical Secondary Rain Forests in Latin America. Today's Challenge, Tomorrow's Accomplished Fact? IKC-NBLF and Stichting BOS, Wageningen, the Netherlands.

Sips, P.A, B.A. van der Linden and K. van Dijk. 1996. The potential of tropical secondary rainforest management in Latin America. (unpublished paper)

Skole, D.L., W.H. Chomentowski, W.A. Salas and A.D. Nobre. 1994. Physical and human dimensions of deforestation in Amazonia. BioScience 44: 314-322.

Smith, J., S. Mourato, E. Veneklaas, R. Labarta, K. Reategui and G. Sanchez. 1997. Willingness to pay for environmental services among slash-and-burn farmers in the Peruvian Amazon: Implications for deforestation and global environmental markets. CSERGE (Centre for Social and Economic Research on the Global Environment). Working Paper. London. (In press)

Swisher, J and G. Masters. 1992. A mechanism to reconcile equity and efficiency in global climate protection: international carbon emission offsets. Ambio 21: 154-159.

Thiele, G. 1995. The displacement of peasant settlers in the Amazon: The case of Santa Cruz, Bolivia. Human Organization 54: 273-282. 
Toledo, J.M., C. Sere and W. Loker. 1989. Pasture-crop technologies for acid soil savannas and rain forests of tropical America. In: R. Meyers (ed.), Innovation in Resource Management, Proceedings of the Ninth Agricutural Sector Symposium, pp. 247-274. World Bank, Washington, DC.

Tomich, T.P, J. Kuusipalo, K. Menz and N. Byron. 1997. Imperata economics and policy. Agroforestry Systems 36: 233-261.

Toniolo, A. and C. Uhl. 1995. Economic and ecological perspective on agriculture in the eastern Amazon. World Development 23: 959-973.

Tropical Science Center (TSC)/World Resources Institute (WRI). 1991. Accounts Overdue: Natural Resource Depreciation in Costa Rica. World Resources Institute, Washington, DC.

Uhl, C. 1982. Recovery following disturbances of different intensities in the Amazon rain forest of Venezuela. Interciencia 7(1): 19-24.

Uhl, C. and D. Nepstad. 1990. Perturbaciones naturales y antropogénicas en la Amazonía. In: A. Anderson (Coord.), Alternativas a la deforestación, pp. 45-76. (Trad. orig. inglés: Alternatives to Deforestation: Steps Toward Sustainable Use of the Amazon Rain Forest). Fundación Natura-Abya Yala-Museo Emilio Goeldi. Cayambe, Ecuador.

Uhl, C., R. Buschbacher and E.A. Serrão. 1988. Abandoned pastures in Eastern Amazonia. I. Patterns of plant succession. Journal of Ecology 76: 663-681.

Villachica, H. 1995. Priorización de árboles multipropósito parea su mejoramiento. Informe de las cinco prieras etapas del proceso de priorización, Lima Perú.

Wadsworth, F.H. 1987. A time for secondary forestry in tropical America. In: J. Figueroa, F.H. Wadsworth and S. Branham (eds.), Management of the Forests of Tropical America: Prospects and Technologies, pp. 189-198. Institute of Tropical Forestry, Rio Piedras, Puerto Rico.

Wadsworth, F.H. 1993. El manejo de los bosques naturales en México tropical, América Central y las islas del Caribe. In: Anais $1^{\circ}$ Congresso Florestal Panamericano. SBS/SBEF. Curitiba, Paraná, Brasil. 19 - 24 Sept. 1993.

Walker R and A.K.O. Homma. 1996. Land use and land cover dynamics in the Brazilian Amazon: an overview. Ecological Economics 18: 67-80.

Walker, R.T., A.K. Homma, A.J. de Conto, R. de Amorim, C. Palheta, A. Moreira dos Santos, A.C. Neves da Rocha, P. Mourao de Oliveira and C.D. Rodriguez. 1993. As contradicoes do processo de desenvolvimiento agricola na transamaronica, Belem. Draft.

Weaver, P.L. 1993. Secondary forest management. In: Management and Rehabilitation of Degraded Lands and Secondary Forests in Amazonia. Proceedings. Santarém, Brazil. April 1993.

Witcover, J. and S.A. Vosti. 1995. Alternatives to Slash and Burn Agriculture (ASB): A Characterization of Brazilian Benchmark Sites of Pedro Peixoto and Theobroma, August/September, 1994. Draft.

Zimmermann, J.K., T.M. Aide, M. Rosario, M. Serrano and L. Herrera. 1995. Effects of land management and a recent hurricane on forest structure and composition in the Luquillo Experimental Forest, Puerto Rico. Forest Ecology and Management 77: 65-76. 